\title{
Sea surface freshwater flux estimates from GECCO, HOAPS and NCEP
}

\author{
By V. ROMANOVA ${ }^{1 *}$, A. KÖHL ${ }^{1}$, D. STAMMER ${ }^{1}$, C. KLEPP ${ }^{2}, A \cdot$ ANDERSSON $^{2}$ \\ and S. B A K A N ${ }^{3}, \quad{ }^{1}$ Institute for Oceanography, KlimaCampus, University of Hamburg, Germany; \\ ${ }^{2}$ Meteorological Institute, KlimaCampus, University of Hamburg, Germany; ${ }^{3}$ Max-Planck Institute \\ for Meteorology, Hamburg, Germany
}

(Manuscript received 5 August 2009; in final form 11 March 2010)

\begin{abstract}
Surface net freshwater flux fields, estimated from the GECCO ocean state estimation effort over the 50 yr period 1951-2001, are compared to purely satellite-based HOAPS freshwater flux estimates and to the NCEP atmospheric re-analysis net surface freshwater flux fields to assess the quality of all flux products and to improve our understanding of the time-mean surface freshwater flux distribution as well as its temporal variability. Surface flux fields are adjusted by the GECCO state estimation procedure together with initial temperature and salinity conditions so that the model simulation becomes consistent with ocean observations. The entirely independent HOAPS net surface freshwater flux fields result from the difference between SSM/I based precipitation estimates and fields of evaporation resulting from a bulk aerodynamic approach using SSM/I data and the Pathfinder SST. All three products agree well on a global scale. However, overall GECCO seems to have moved away from the NCEP/NCAR first guess surface fluxes and is often closer to the HOAPS data set. This holds for the time mean as well as for the seasonal cycle.
\end{abstract}

\section{Introduction}

Net freshwater fluxes at the ocean surface play an important role in coupling the ocean with the atmosphere, with the continents as well as with the cryosphere. Over the open ocean, net freshwater fluxes are associated with two different and distinct mechanisms, evaporation being one of them, associated with the latent heat loss of the ocean to the atmosphere. The other component is associated with precipitation over the ocean which exhibits a complex space-time pattern and shows enhanced values especially along the intertropical convergence zone (ITCZ) and over mid-latitude storm tracks. River run-off and ice melting are the other important sources of freshwater at the surface of the ocean. To remain near a steady state, local imbalances of net air-sea flux of freshwater have to be compensated by freshwater convergences or divergences of atmospheric moisture transports or of ocean freshwater transports and transports of sea ice.

Once entering the ocean, freshwater alters the salinity and thereby the density field and the circulation of the ocean. Because of the importance of freshwater forcing for the ocean

\footnotetext{
*Corresponding author.

e-mail: vanya.romanova@pik-potsdam.de, recently at Potsdam Institute for Climate Impact Research, 14412 Potsdam, Germany DOI: $10.1111 /$ j.1600-0870.2010.00447.x
}

circulation, a detailed knowledge of the surface freshwater forcing is of major concern in climate research. Knowledge of many aspects of the surface net freshwater forcing (including river run-off and glacier melting) is lacking (even the time mean is not well determined, let alone its variability) and improving our knowledge about surface freshwater fluxes poses observational challenges. The residual nature of the freshwater fluxes will cause the errors to be larger than those from the individual products. The strong deviations of the estimates of the precipitation fields are shown in Beranger et al. (2006). The estimates of the evaporation is dependent on the accuracy of the turbulent heat fluxes and the assumptions applied for deriving them. However, model based products are more likely to be balanced compared to the observationally derived ones. A review of the state of the knowledge about ocean surface freshwater fluxes and ocean freshwater transports is provided by Wijffels (2001). Estimates of freshwater discharge from continents in terms of river run-off are provided by Dai and Trenberth (2002). From hydrographic sections, Talley (2008) recently investigated transport and redistribution of freshwater in the ocean through the ocean circulation.

Further progress in our understanding of surface freshwater flux fields, which at this point is much higher than uncertainties in net heat flux, requires the exploitation of new in situ and satellite based technologies and the integration of measurements 
and modelling alike, for example, as it is being pursued in atmospheric re-analysis efforts, which are being used heavily as source of surface freshwater flux fields. However, while being of enormous value for many aspects of oceanographic and climate studies, atmospheric re-analyses all suffer at some level from problems in their freshwater budgets (Trenberth and Guillemot, 1998; Beranger et al., 1999; Leung et al., 2003; Josey and Marsh, 2005; Schlosser and Houser, 2006; Trenberth et al., 2007; Xie et al., 2007).

A different route to inferring surface net freshwater fluxes was pursued by Jourdan et al. (1997) who used satellite radiometric data over a 3 yr period (1988-1990) to compute surface freshwater fluxes. Sohn et al. (2004) developed a methodology for deriving atmospheric water vapour transports over the world ocean from satellite-retrieved precipitation and evaporation data sets, using SSM/I (Special Sensor Microwave Imager) and TRMM (Tropical Rainfall Measuring Mission) data sets from the 7-yr period 1988-1994. Finally, Mehta et al. (2005) investigated the annual cycle of the global hydrological cycle using remote-sensing based estimates of precipitation from the Global Precipitation Climatology Project (Adler et al., 2001) and evaporation fields from Goddard Satellite-Based Surface Turbulent Fluxes (GSSTF) data. While providing promising results, it also became obvious that uncertainties remained large in those early satellite-based products. Recently, the Hamburg Ocean Atmosphere Parameters and Fluxes from Satellite data project (HOAPS) provided a new set of surface fluxes derived from satellite data (Andersson et al., 2007) which will be used in this study.

Because of all the difficulties in measuring surface freshwater fluxes directly, or in estimating them through atmospheric re-analyses or satellite observations, significant effort has been placed on estimating surface net freshwater fluxes from the divergence of ocean freshwater transports inferred through ocean inverse calculations (see Talley, 2008). As an example, MacDonald (1998) and Ganachaud and Wunsch (2003) used an inverse box model based on hydrographic sections for the estimation of oceanic fluxes of mass, heat and freshwater. Today, time-dependent ocean syntheses play an important role in estimating the ocean circulation and ocean transports as well as surface fluxes of heat, freshwater and momentum. They are obtained by merging all available ocean data with a numerical model to estimate the time-varying ocean circulation and required surface forcing fields (Wunsch, 1996; Stammer et al., 2002). Based on the 11-yr ECCO-SIO synthesis described in detail by Köhl et al. (2007), Stammer et al. (2004) analysed the estimated surface heat fluxes and found that outside boundary current regions, the adjustments of surface freshwater fluxes appear to be in agreement with independent fluxes provided by Large and Yeager (2004).

Expanding on the work of Stammer et al. (2004), this study focuses on an analysis of net surface freshwater fluxes provided by the $50-\mathrm{yr}$ long GECCO (German ECCO) ef- fort (Köhl and Stammer, 2008a,b) and compares them with the newly available and purely satellite-based estimates of net surface freshwater fluxes provided by the HOAPS project (Andersson, 2009) and with the NCEP/NCAR re-analysis 1 (NCEP hereafter; see Kalnay et al., 1996, for details) net surface fluxes. The goal of the study is, to provide new insight into global and regional surface freshwater forcing fields of the ocean and their temporal variability. Moreover, by performing this threeway intercomparison, we aim to jointly test the quality of the GECCO and HOAPS freshwater fluxes against each other and to investigate if they have coherent differences relative to the NCEP. The independent information that is introduced by GECCO synthesis can be evaluated through the GECCO NCEP differences to assess how much GECCO moves away from NCEP.

The remaining paper is organized as follows. In Section 2, the method is summarized. Differences between time-mean surface freshwater flux estimates, trends, seasonal cycle and interannual variability are discussed in Section 3 and Section 4 analyses integral freshwater quantities. The comparison is performed on a global basis in terms of time-mean fields and their seasonal cycle and in terms of implied ocean transports. Inferred ocean freshwater transports, with specific focus on the North Atlantic freshwater budget, are provided in Section 5. Concluding remarks follow in Section 6.

\section{Data sets}

Our analysis is based on monthly mean net surface freshwater flux fields provided by the GECCO and HOAPS projects over the period 1988-2001. Throughout the paper we define positive freshwater fluxes as entering the ocean.

\subsection{GECCO}

The global GECCO ocean state estimate is an extension of the earlier 11-yr ECCO-SIO solution of Köhl et al. (2007) and is covering the 50-yr period 1952-2001. Details on the estimation process are provided by Köhl and Stammer (2008a,b), and only a brief summary of the estimation methodology is therefore provided here. Important for this study is that, unlike a number of other existing ocean state estimates, the ECCO approach is directed at obtaining estimates of the time evolving ocean circulation that are consistent with the dynamics embedded in a general circulation model, without adding any artificial sources or sinks of heat, freshwater or momentum. The estimation is based on the ECCO adjoint ocean general circulation model, which is derived from the MIT (Massachusetts Institute of Technology) model (Marshall et al., 1997a,b). Prognostic variables are the three dimensional fields of velocity, heat, salt and the sea surface height.

The model has a horizontal resolution of $1^{\circ}$ and a latitudinal coverage of $80^{\circ} \mathrm{S}$ to $80^{\circ} \mathrm{N}$, with 23 vertical levels. It is initialized with Levitus et al. (1994) climatological January potential 
temperature and salinity fields and is driven by NCEP daily surface heat and freshwater fluxes and twice daily wind stress fields. The freshwater flux from NCEP is transformed to a virtual salt flux (Barnier, 1998) without using a restoring term. However, the forcing function which moves the forcing away from original NCEP (Gulev et al., 2003), in our case is based on the adjustments of the fluxes by minimizing the model data misfit within 23 iterative steps. The river runoff is prescribed in the present assimilation run and is added as a time constant to the freshwater flux. It is obtained from the estimates of the climatological differences between precipitation and evaporation over each continent, and partitioned into catchment areas for the different ocean basins (Fekete et al., 1999).

The adjoint model is used to iteratively reduce the modeldata misfit. By sweeping forward and backward, the control vector is systematically modified through the Lagrange multiplier method. Together with the initial temperature and salinity fields, the surface wind stress, the net heat flux, and the net surface freshwater flux are part of the control vector; that is, it is being adjusted so that the model best simulates observed ocean parameters. The data used as constrains during the assimilation include several satellite data sets (e.g. sea surface height, sea surface temperature fields), surface drifter velocities, in-situ hydrographic temperatures and salinity profiles as well as WOCE hydrographic sections. The models monthly mean climatologies of temperature and salinity are constrained through the Levitus et al. (1994) climatology and the surface forcing fields are constrained through daily NCEP surface fluxes. A detailed description of the data sets and their prior errors are given by Köhl et al. (2006).

\section{2. $H O A P S$}

The HOAPS methodology and climatology are described in detail by Andersson (2009). It utilizes data from the SSM/I operating on the polar orbiting Defense Meteorological Satellite Program (DMSP) satellites to retrieve basic state variables from which individual components of surface fluxes of heat, evaporation, and precipitation are derived. The net freshwater flux fields used in this study are calculated as the difference between the precipitation and evaporation (P-E) on a $0.5^{\circ}$ grid (available at www.hoaps.org). Because a specific goal of the HOAPS effort is to estimate the global ocean freshwater flux continuously from satellite based data, great care was put into intersensor calibration from different satellites for a homogeneous and reliable spatial and temporal coverage. Due to the use of all available SSM/I instruments at a given time, a spatially homogeneous data sampling is achieved with an average of about 350 observations per gridbox and month over the entire data record. The sampling is globally consistent and, apart from regions with varying sea ice coverage, no latitudinal dependence of the number of observations is evident. All HOAPS variables are derived from brightness temperature measurements of the SSM/I radiometers.
To rely exclusively on satellite data for the computation of latent and sensible heat flux parameters, the additionally needed SST information is taken from Advanced Very High Resolution Radiometer (AVHHR) measurements. Also, a sea ice detection procedure based on the NASA Team algorithm has been implemented (Swift et al., 1985).

HOAPS latent heat flux retrieval is based on the bulk aerodynamics COARE 2.6a algorithm of Fairall et al. (1996, 2003). The sea surface saturation specific humidity is calculated by applying the Magnus formula to the AVHRR SST measurements with an additional salinity correction by a factor of 0.98 . The near surface wind speed, which is directly derived from the SSM/I measurements in HOAPS, is dynamically coupled to short ripple waves and foam coverage of the ocean surface and in turn influences the surface emissivity and thus the upwelling radiances (Schlüssel, 1995). In order to attribute for the nonlinearity of the problem, a neural network approach is used in HOAPS to derive the wind speed. This neural net was trained with a composite of buoy match-ups and radiative transfer calculations (cf. Andersson et al., 2010). Over the oceans, the near surface atmospheric specific humidity is strongly correlated with the water vapour content in the lower boundary layer (Schulz et al., 1993). Schlüssel (1996) developed a model to derive it directly from SSM/I measurements based on the 19, 22 and $37 \mathrm{GHz}$ channels. HOAPS uses a refined version of this linear relationship (Bentamy et al., 2003). Similar to the wind speed retrieval, the HOAPS precipitation algorithm is based on a neural net approach. The neural network was trained with a data set of assimilated SSM/I brightness temperatures and the corresponding precipitation values of the European Centre for Medium-Range Weather Forecast (ECMWF) model (Bauer et al., 2006). The resulting retrieval algorithm is independent of any ancillary information and relies exclusively on SSM/I brightness temperatures.

A detailed quantitative uncertainty description for the satellite based HOAPS flux parameters is difficult and thus not yet available, albeit an error model for the retrieval procedures would be generally highly desirable. The lack of reliable and comprehensive in situ data over the oceans limits such validations mostly to intercomparison studies with a more qualitative than a quantitative error description. Further difficulties are connected with the different temporal and spatial scales of the in situ measurements compared to the satellite data. For the evaporation parameter Bourras (2006) showed that HOAPS is well suited for global applications. In the comparison with other products differences on the global scale between $5-10 \%$ are reported in Andersson (2009). The individual input parameters to the bulk flux algorithm have also been evaluated with good results (Winterfeldt et al., 2009; Bentamy et al., 2003; Andersson et al., 2010). However, in regions of high aerosol load (e.g. originating from desert dust, biomass burning or volcanic eruptions such as Mt Pinatubo in 1991) the accuracy of the SST data could be impaired as would be the evaporation retrieval and thus the 
net HOAPS surface freshwater flux product. Also, Schlosser and Houser (2006) point out uncertainties with the long term development of available evaporation time series.

The evaluation of precipitation is even more complicated due to the strong variability in the in situ measurement of this parameter over the ocean. Previous intercomparison studies, including satellite and model data, showed regionally large differences among the individual products that are up to $50 \%$ in regions of strong precipitation and at high latitudes (e.g. Adler et al., 2001; Beranger et al., 2006). Other studies indicate a systematic underestimation up to $15 \%$ by other satellite based products compared to tropical atoll and buoy data (Adler et al., 2001; Bowman et al., 2009; Sapiano et al. 2009). On the other hand, the model based data, for example, re-analysis products, are found to perform significantly poorer than observational fields in particular in the tropical regions (Trenberth and Guillemot, 1998; Janowiak et al., 1998; Schinoda et al., 1999). However, the new approach in HOAPS-3 precipitation retrieval exhibits good agreement with other products in spatial patterns and global mean values (Andersson, 2009). Some larger differences occur in the northern ITCZ region of the central Pacific, where HOAPS precipitation is about $20 \%$ higher compared to the Global Precipitation Climatology Project (GPCP) and Tropical Rainfall Measuring Mission (TRMM) satelite data.

\section{Global surface freshwater flux estimates}

We compare GECCO and NCEP products to HOAPS data for the overlapping time period from 1988 to 2001 on a $1^{\circ}$ spatial resolution. The products have different land-ocean masks. As HOAPS does not contain any retrievals at pixels over sea-ice and near coastal lines, the spatial extent is smaller than GECCO. Therefore, the comparisons will be limited to a common surface area, determined by the HOAPS coverage (Figs. 2, 4, 6 and 9). However, when computing zonal integrals and ocean transports, the full data coverage of individual data sets is being used (except for NCEP, in which the ocean flux is restricted by the GECCO land mask). For areas covered with sea ice, GECCO fluxes describe the transfer at the ice-ocean interface, thus including freezing and melting processes, while NCEP fluxes describe the transfer at the atmosphere-ice interface.

\subsection{Time-mean fields}

Figure 1 shows global ocean time-mean net freshwater flux fields into the ocean as precipitation minus evaporation, P-E, evaluated from NCEP, GECCO and HOAPS. The patterns agree well on the symmetric structure characterized by ITCZ with enhanced precipitation north of the equator and tropical subduction zones with enhanced evaporation north and south of the ITCZ. Comparing NCEP with HOAPS or GECCO, the maximum net evaporation is shifted from the eastern subtropical Pacific into central subtropical North Pacific. A similar shift can be seen
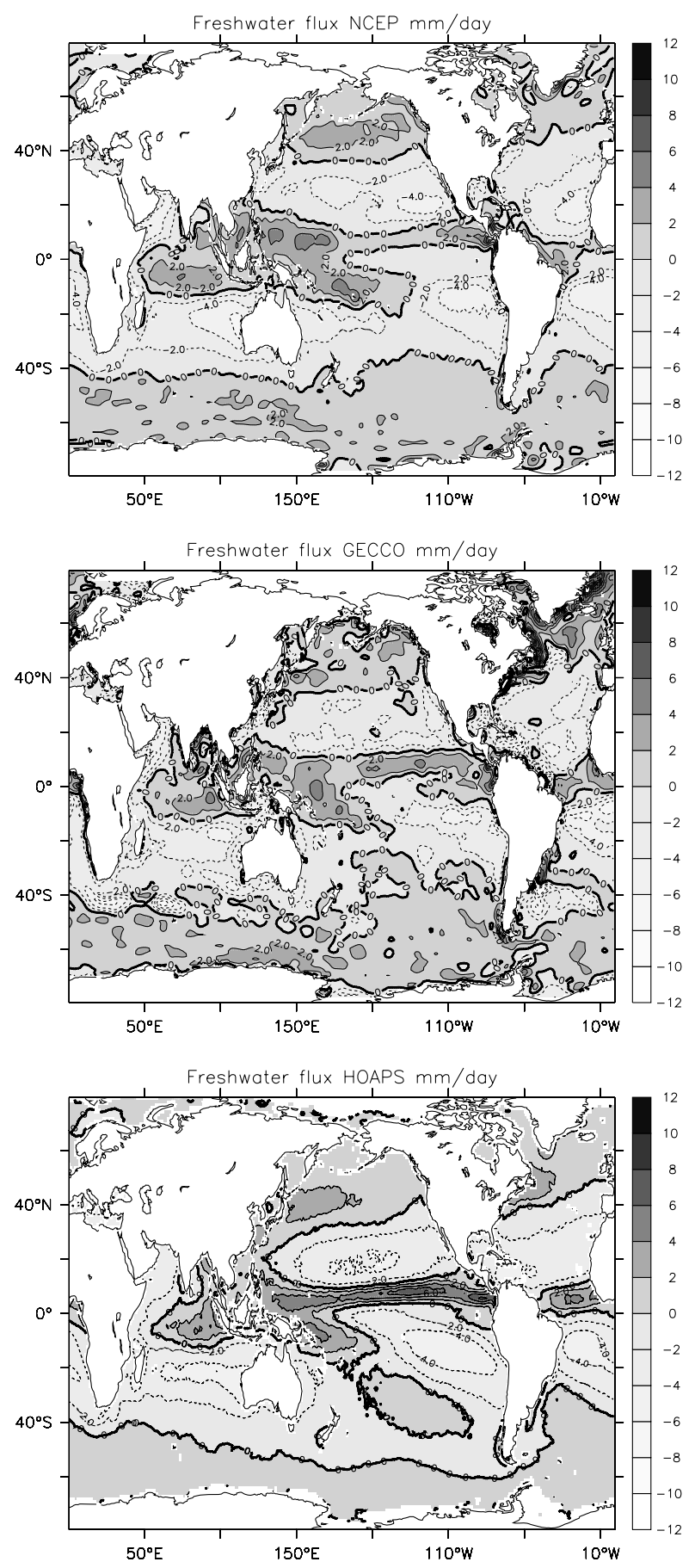

Fig. 1. Time-mean net freshwater flux fields evaluated from NCEP (top panel), GECCO (middle panel), and HOAPS (bottom panel). All fields were evaluated over the identical period 1988-2001. Positive values indicate a net freshwater flux into the ocean. The contour increment is $2 \mathrm{~mm} \mathrm{~d}^{-1}$ in all panels.

in the Atlantic where the maximum evaporation occurs in the Caribbean. The midlatitudes, around $30^{\circ}$ and $40^{\circ}$ latitude in the Northern and Southern Hemisphere, show dominating precipitation patterns with maxima over the western boundary currents 
such as the Gulf Stream or the Kuroshio. The mean freshwater flux values are largest for HOAPS in the ITCZ reaching $10 \mathrm{~mm} \mathrm{~d}^{-1}$ and in the central Pacific, GECCO shows intermediate values up to $4 \mathrm{~mm} \mathrm{~d}^{-1}$ while NCEP shows the smallest values up to $2 \mathrm{~mm} \mathrm{~d}^{-1}$. In contrast to NCEP which is known to underestimate the strengths of the ITCZ (e.g. see Trenberth and Guillemot, 1998), HOAPS and GECCO show well defined ITCZ in the Atlantic Ocean. On the other hand the high level of precipitation in HOAPS product needs to be tested against other products (in situ measurements are rare in that region).

The largest differences of GECCO freshwater flux relative to HOAPS and NCEP exist mainly over parts of Labrador Sea and around Greenland and along the coastal margins, e.g. in the Amazon delta or off the Rio de la Plata mouth (Fig. 2). This could be associated with the ice import and melting and river discharge which are included in the correction procedure by changing the net freshwater input through the surface. In addition, we seem to find ocean and atmospheric frontal structures in the differences field. Most clearly this can be identified along the Agulhas Current, the Gulf Stream and North Atlantic Current and equatorward of the Malvinas Confluence region in the subtropical gyre of the South Atlantic.

One impact of the differences of the time-mean P-E fields between GECCO and HOAPS on driving an ocean circulation model can be discussed in the framework of earlier work by Huang and Schmitt (1993), who estimated that the volume flux associated with the surface freshwater flux drives an equivalent Goldsbrough-Stommel circulation that can be as large as $10 \%$ of the wind-driven flow. The authors estimated a southward western boundary current of about $2 \mathrm{~Sv}$ in mid-latitude of the North Atlantic. Projecting their results on the flux differences shown in Fig. 2, differences of the order of $1 \mathrm{~Sv}$ in the barotropic circulation could result in the North Atlantic depending on which surface forcing is being used.

\subsection{Seasonal cycle and trends}

Considerable interest exists in the variations on the seasonal cycle. We therefore estimated the seasonal cycle of the NCEP, GECCO and HOAPS surface freshwater fields by least-squares fitting an annual harmonic to the monthly mean fields over the period 1988-2001. Respective amplitudes and phase fields are shown in Fig. 3. The amplitudes are comparable in all products and largest amplitudes of up to $12 \mathrm{~mm} \mathrm{~d}^{-1}$ are located in the subequatorial areas around the ITCZ in the Atlantic and Pacific, in the Indian Ocean and the western part of the South Pacific. Only in the eastern tropical Pacific, NCEP and GECCO show significantly smaller amplitudes than HOAPS. The phases clearly show the seasonal shift of the ITCZ with more precipitation in the tropics during the summer months over the Northern Hemisphere and more precipitation in the tropics in the winter months in the Southern Hemisphere. Again in the polar regions, patterns of amplitude and phase differ considerably.
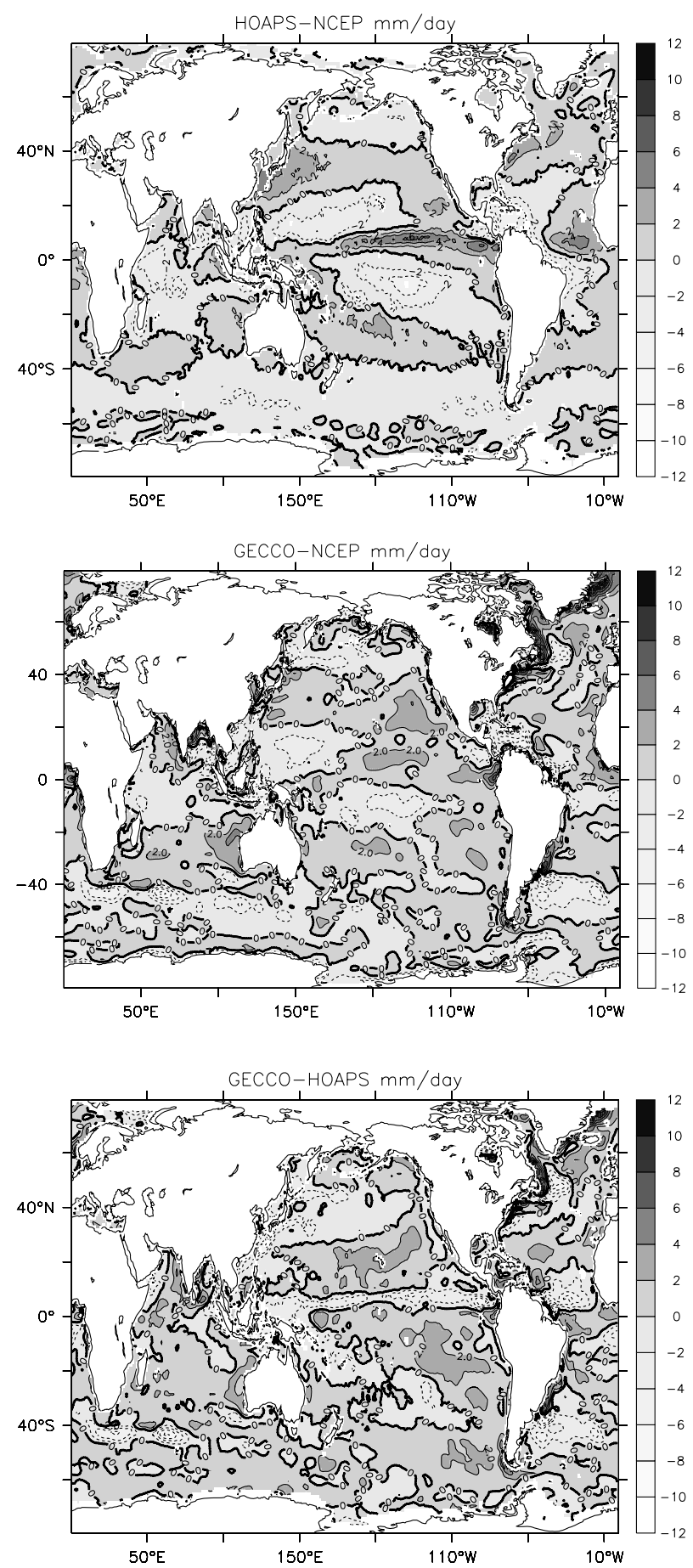

Fig. 2. Time-mean freshwater flux differences of HOAPS-NCEP (top panel), GECCO-NCEP (middle panel) and GECCO-HOAPS (bottom panel), all evaluated over the period 1988-2001. In all panels the contour increment is $2 \mathrm{~mm} \mathrm{~d}^{-1}$.

Figure 3 suggests that, while the amplitudes of the seasonal cycle in NCEP, GECCO and HOAPS are in general agreement, conspicuous differences remain in terms of phase. To quantify this, we show in Fig. 4 the seasonal cycle of all three zonal mean 

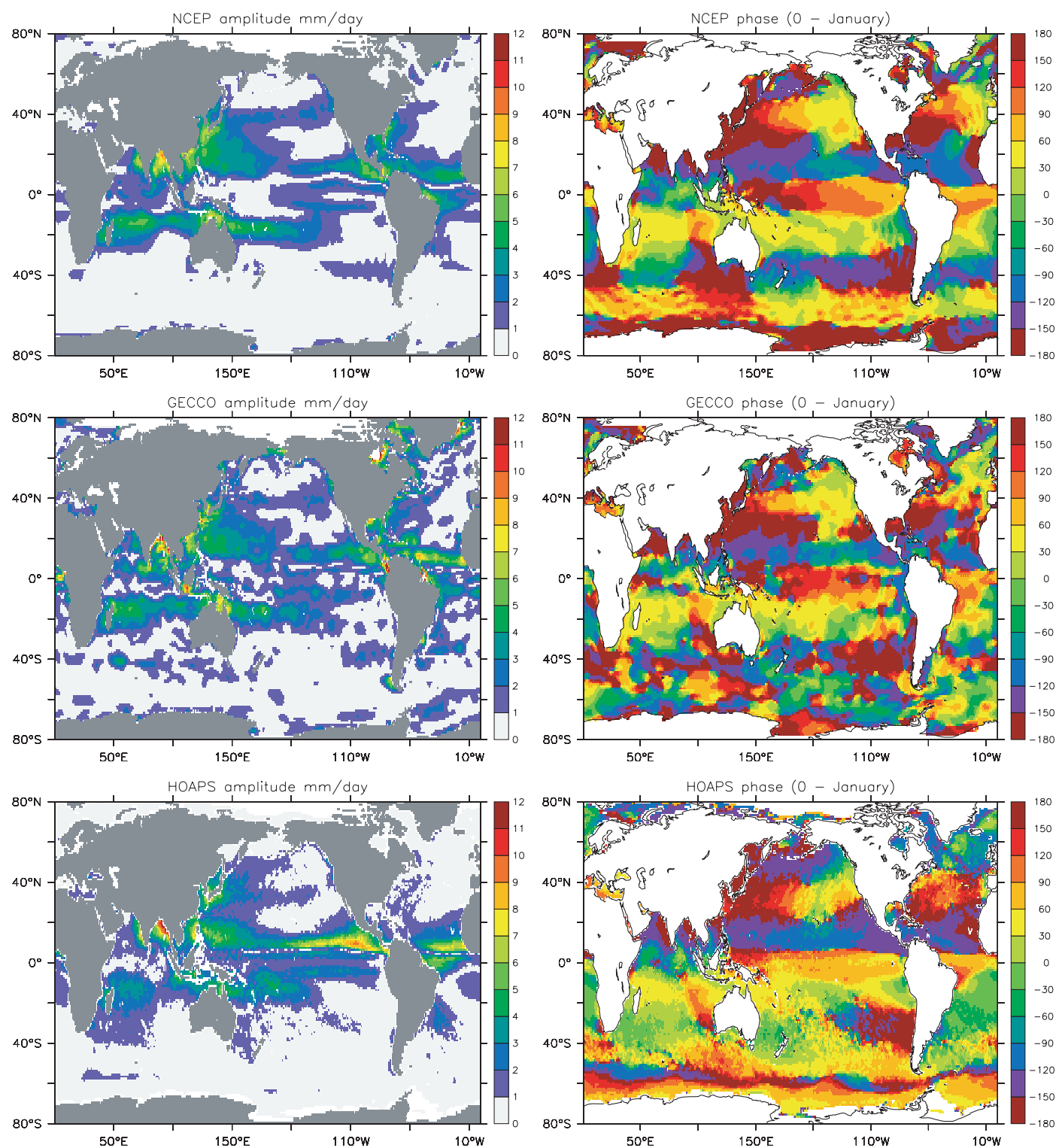

Fig. 3. Amplitude (left-hand panel) and phase (right-hand panel) of the annual harmonics of the NCEP (upper panel) GECCO (middle panel), and HOAPS (bottom panel) freshwater flux fields. Amplitudes are in $\mathrm{mm} \mathrm{d}^{-1}$ and phases are referenced to January 1.

surface freshwater fluxes. Large P-E signals exists in all three estimates over the ITCZ which are a result of intense precipitation there; however they appear to be strongest in HOAPS, while in GECCO the signal is intermediate and weakest is NCEP. In all three products $\mathrm{P}-\mathrm{E}$ migrates with the ITCZ meridionally, reaching its maximum northward position in about August in HOAPS, while in NCEP it is reached in September. Moreover, net precipitation in the ITCZ is strengthened in summer months, and is smallest in January and February. This also holds for GECCO, which shows a maximum $\mathrm{P}-\mathrm{E}$ in November, with a secondary maximum in June. Between the ITCZ and $40^{\circ}$ latitude we find belts in which the evaporation predominates. Those belts migrate meridionally on the seasonal cycle while at the same time show a pronounced strength in all three estimates. Maximum and minimum values can be found in January/February in the northern hemisphere and in July-August in the southern hemisphere, respectively. A secondary maximum exists north of $50^{\circ} \mathrm{N}$ in January. GECCO and NCEP both show a meridional migration, but a weaker variation in the strength. The high positive net freshwater fluxes in the high northern latitudes of the GECCO results is associated with the signal of sea ice melt and freshwater discharge in the summer months over the polar region, a feature that is missing in NCEP and HOAPS.

(Fig. 5) shows the linear trends significant at the 95\% level according to a Student's t-test for the slope of the regression line at each grid point. The seasonal variability was removed before 

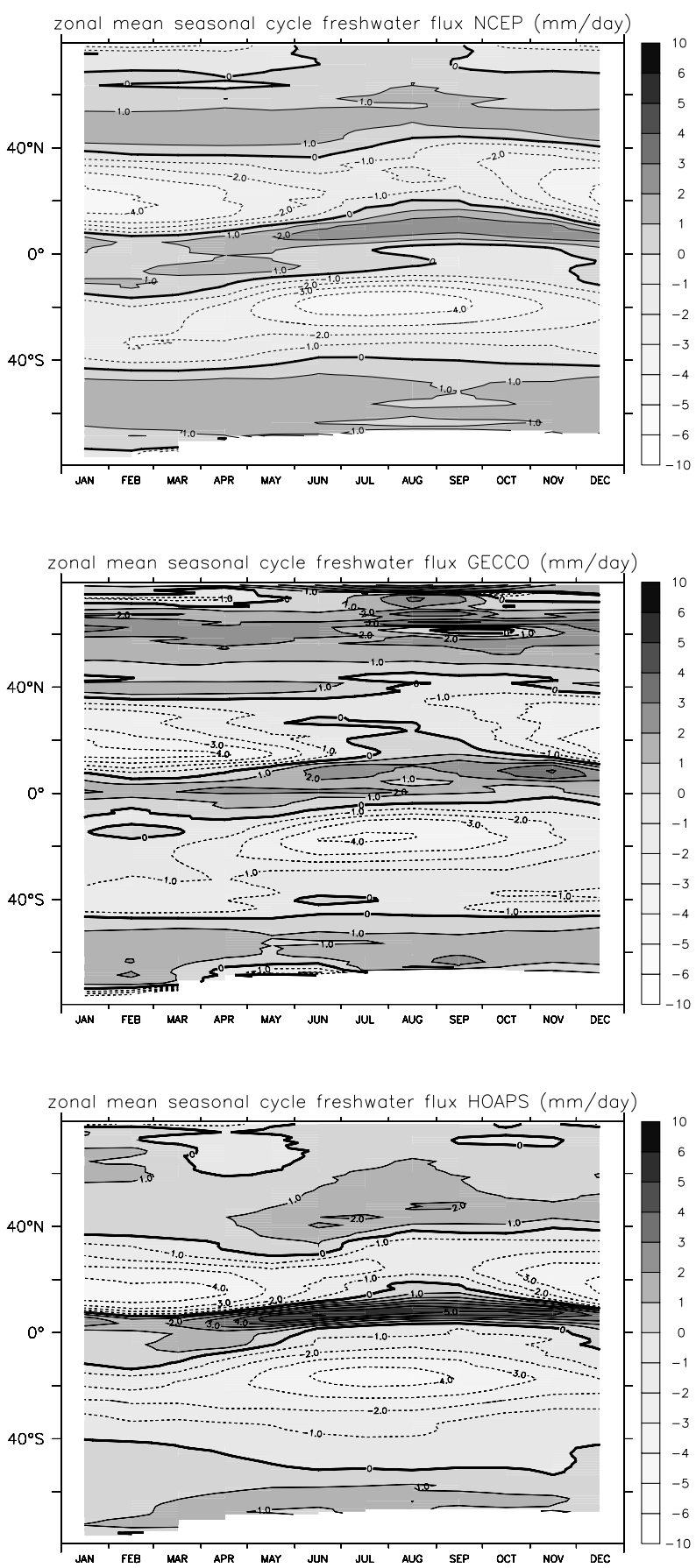

Fig. 4. Climatological seasonal cycle of the zonally averaged surface freshwater flux fields for NCEP (top panel), GECCO (middle panel) and HOAPS (bottom panel) in $\mathrm{mm} \mathrm{d}^{-1}$.

the calculation. For all freshwater flux products the freshwater trends are typically a few $\mathrm{mm} \mathrm{d}^{-1}$ per decade and for the entire overlapping period of $14 \mathrm{yr}$ contributing a significant change to the mean freshwater flux in many regions. Notable is that area and size of positive trends are not balanced by the area and size of the negative trends which leads to a mean negative
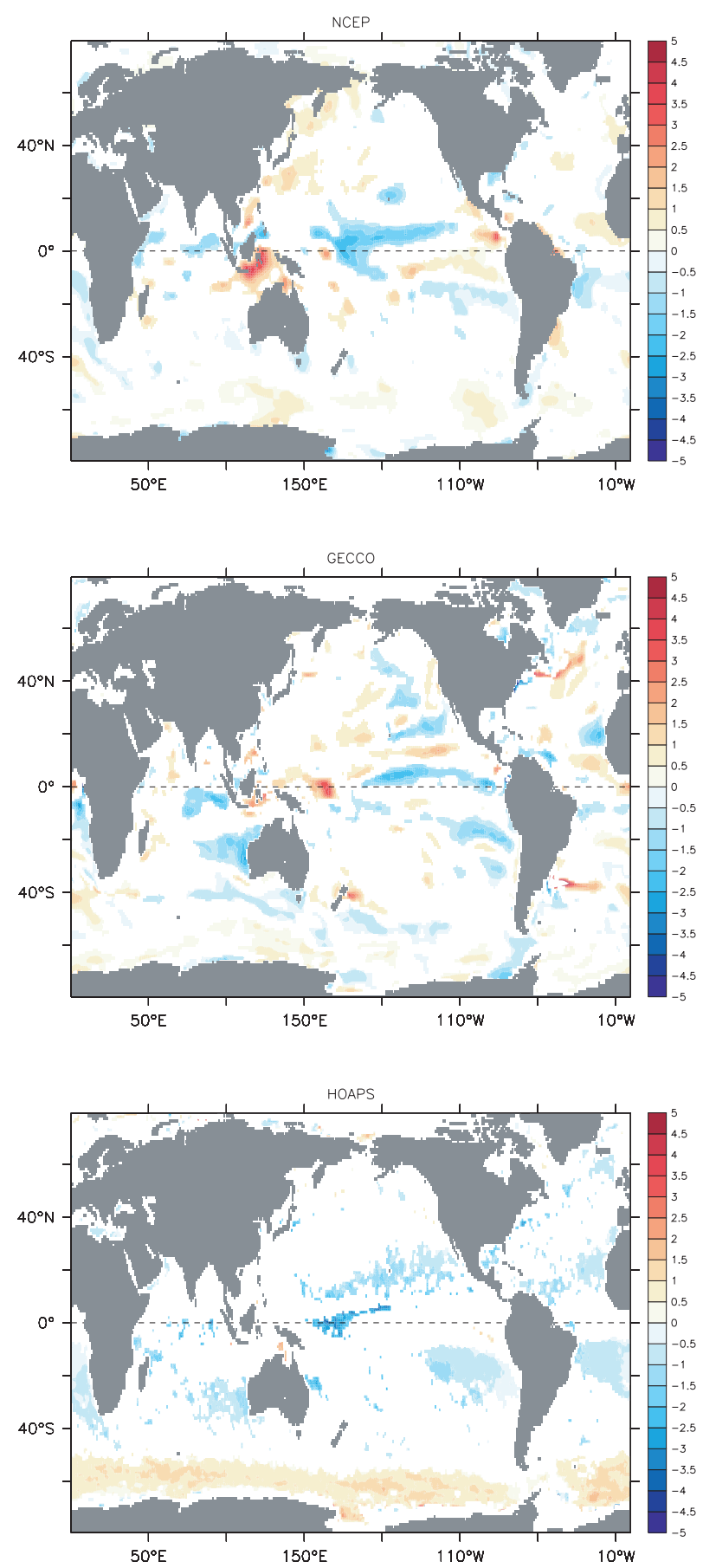

Fig. 5. Linear trends of the freshwater fluxes from NCEP (upper pannel), GECCO (middle pannel) and HOAPS (bottom pannel) shaded for trends significant at the $95 \%$ level. The units are in $\mathrm{mm} \mathrm{d}^{-1}$ per $10 \mathrm{yr}$.

trend implying an increasing transport of freshwater from the ocean to the land. This is most pronounced for HOAPS which global negative trend equals $-0.47 \mathrm{~mm} \mathrm{~d}^{-1}$ per decade but different for GECCO and NCEP where positive and negative pattern 
are nearly balanced (respectively -0.07 and $-0.04 \mathrm{~mm} \mathrm{~d}^{-1}$ per decade). Common for all three products are the $\mathrm{P}-\mathrm{E}$ reduction over the central Equatorial Pacific, P-E increase over the Indonesian Throughflow region and the negative trends in the eastern tropical Pacific in the Southern Hemisphere. Trends with opposite signs exist over western boundary currents in GECCO and HOAPS products in contrast to NCEP where the trend is very small. The most pronounced feature in HOAPS is the change in sign of the trend slightly north of $60^{\circ} \mathrm{S}$ where the maximum of the sea ice extend is located. This precipitation increase over the Southern Ocean is only partly expressed in the NCEP and GECCO which albeit show a different pattern there that include also regions with negative trends. It remains therefore questionable whether this trend is an expression for a shifting climate or related to problems in the retrieval over sea ice covered regions. Further in the study, the calculated trends are removed from each data set.

\subsection{Interannual variability}

The temporal variability present in the monthly mean time series of all three data sets outside the annual frequency is displayed in Fig. 6 in terms of their overall standard deviation (STD) inferred from the period 1988-2001.

To compute the fields, a seasonal cycle was removed from each time series prior to the computation of the STD. Additionally, a spatial Hanning filter with a 5 points window width was applied to HOAPS. The mean variability is largest in the HOAPS estimate (1.74 versus 1.33 , and $1.28 \mathrm{~mm} \mathrm{~d}^{-1}$ for GECCO and NCEP, respectively) which shows high STD values coincident with regions of large freshwater input into the ocean, that is, regions of high net precipitation. Enhanced variability can likewise be seen along the equator and in the western tropical Pacific, in the Gulf of Bengal, over the subtropical gyre of the South Atlantic and South Pacific and along the path of the North Atlantic Current. All other regions show only minor temporal variability. The second harmonic for all three patterns (not shown) confirms the enhanced interannual variability with amplitudes of 2-4 $\mathrm{mm} \mathrm{d}^{-1}$ over the Atlantic equatorial regions connected with the variability of ITCZ; over Indian Ocean connected with Monsoons and the subequatorial Pacific in the Northern Hemisphere attributed to ENSO signal. A physical explanation for the relatively high variability in the HOAPS freshwater fluxes would point towards various processes leading to higher variability. Among them could be the different sampling rate (especially in space) by the satellite. But from the variability pattern it is apparent that much the variability is caused by variability in the underlying precipitation fields which in HOAPS are much stronger than in NCEP.

Since GECCO has only the time-mean run-off prescribed, significant run-off variability is being included and is being compensated in the estimation by enhancing net freshwater fluxes through the surface near river mouths, for example, by
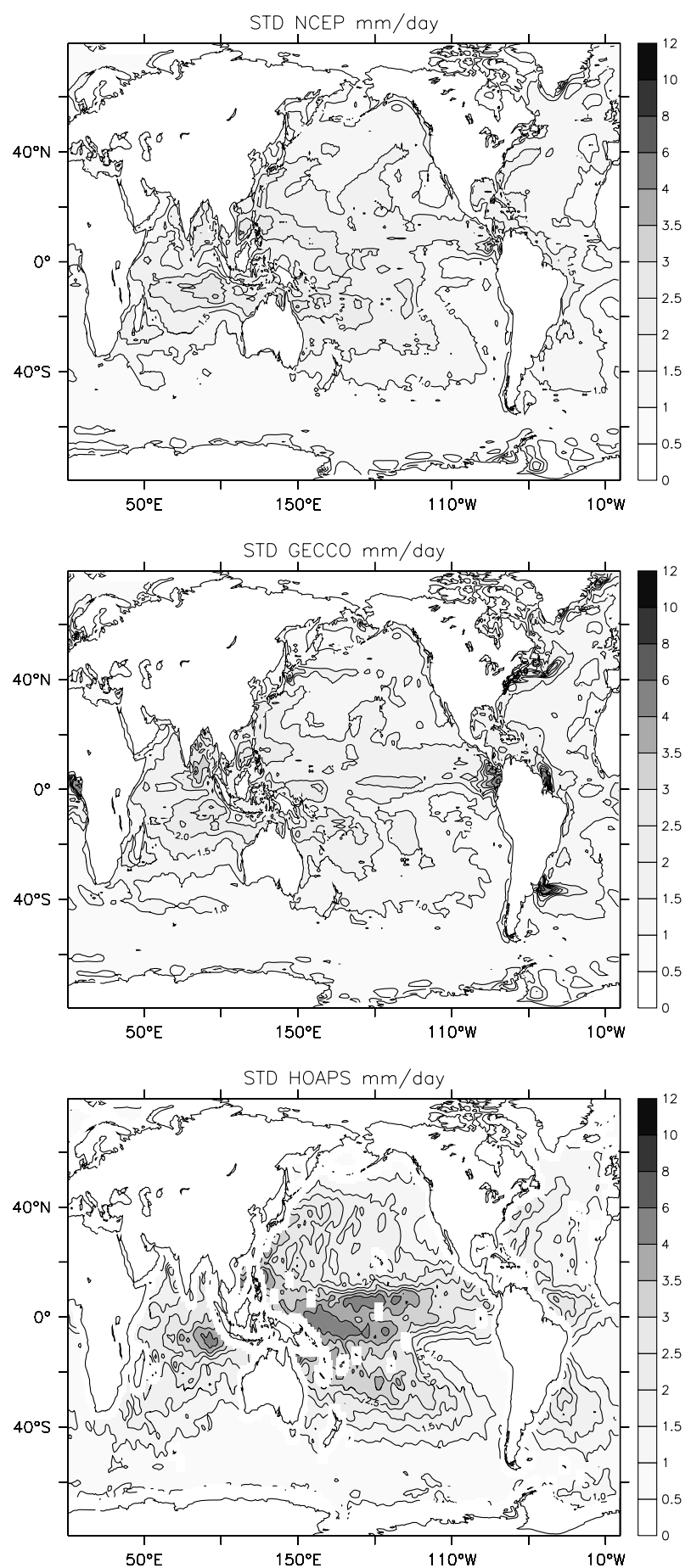

Fig. 6. Standard deviation (STD) evaluated from monthly mean net freshwater flux fields over the period 1988-2001 from NCEP (top panel), GECCO (middle panel) and HOAPS (bottom panel). A seasonal cycle was removed from each field and a spatial Hanning filter was applied to HOAPS. All panels have the same contour increments on a non-linear scale. 
enhancing the seasonal cycle of net freshwater fluxes there. Regions where this can be found include the Amazon River, Parana and Congo River, Rio del Plata and the Ganges river. Run-off is neither part of NCEP nor of HOAPS and a respective pattern therefore has to be absent. Moreover, the high variability east of Greenland is most likely a result of sea ice melting estimated from assimilating salinity data at that location. This holds likewise — albeit with smaller amplitude - to the east Greenland current and the northern Labrador Sea. We also note the enhanced variability along strong frontal structures, such as the Gulf Stream and especially along the Antarctic Circumpolar Current (ACC) where possibly fluctuations of the frontal position might be projected onto the surface forcing to bring the model closer to the observed salinity variations in those regions.

Unlike the GECCO mean surface freshwater flux estimate that was significantly altered away from the NCEP first guess through the estimation procedure, the surface freshwater flux variability in GECCO remains more or less that of the NCEP field, that is, not enough information exist in the prescribed ocean data about changes in surface salinity and associated surface freshwater forcing. This is confirmed by a map of the correlation between GECCO and NCEP monthly mean surface freshwater flux fields shown in Fig. 7 (the linear trends and the seasonal cycles are removed). Regions with correlations smaller than the 0.46 significance limit (at a $95 \%$ confidence limit) are concentrated where runoff and sea ice melting is important, including some areas in the Southern ocean (e.g. Weddell Sea). Additional areas of low correlations are found in the eastern Pacific and Atlantic, in the areas of the cold tongues. Trenberth and Guillemot (1998) identified problems in the NCEP surface freshwater fields on the annual period especially in the tropics. This may have been remedied in the GECCO estimates through the adjustment of the surface boundary conditions, although the effect on the tropical variability is apparently small (compare Fig. 6).

HOAPS and NCEP estimates are largely independent of each other. Accordingly the correlations are overall lower as compared to GECCO and NCEP (Fig. 7b). The same holds for the correlation between HOAPS and GECCO fields (Fig. 7c). However, the correlation is significant between $50^{\circ} \mathrm{S}$ and $50^{\circ} \mathrm{N}$ where the coefficients are largely between 0.4 and 1 . Exceptions reside in regions of ITCZ in the Pacific and Indian Oceans and over the southern tropics of the Atlantic Ocean. The Southern Ocean shows negative correlation with value up to -0.4. Possible reasons for the low correlation in the polar regions include the lack of data (atmosphere and ocean) there.

\section{Global freshwater transports}

With the large differences in net water balance in the oceans (the Pacific Ocean gains about $0.5 \mathrm{~Sv}$, the Atlantic Ocean loses on average over $1 \mathrm{~Sv}$ according to Baumgartner and Reichel
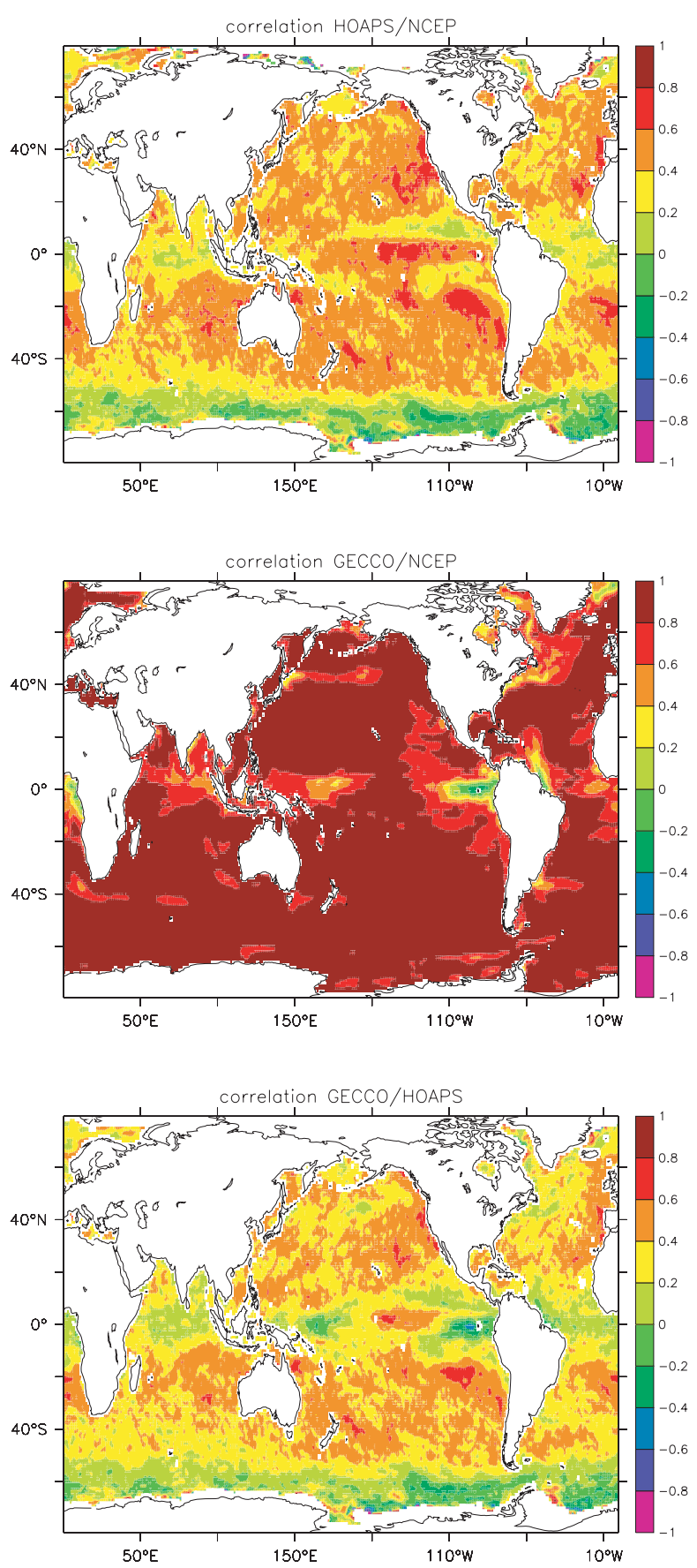

Fig. 7. Correlation coefficients between HOAPS and NCEP (top panel), GECCO and NCEP (middle panel), and GECCO and HOAPS (bottom panel), evaluated from monthly mean freshwater flux fields over the period 1988-2001 (the linear trends and the climatological seasonal cycles were removed). In all panels the contour increment is 0.2 .

(1975), it is clear that significant volumes of freshwater must be redistributed between the various basins. This water movement is partly accomplished by the interbasin connections of the Bering Strait, the Indonesian Through Flow, and the Southern Ocean. In 
Table 1. Surface freshwater flux (P-E) for NCEP, GECCO and HOAPS, averaged globally(top line) and over various latitudinal ranges as indicated in the table

\begin{tabular}{lcrr}
\hline lat. belt & NCEP & GECCO & HOAPS \\
\hline $80^{\circ} \mathrm{S}-80^{\circ} \mathrm{N}$ & -0.554 & -0.387 & -0.658 \\
$60^{\circ} \mathrm{N}-80^{\circ} \mathrm{N}^{\star}$ & 0.258 & 1.511 & 0.459 \\
$40^{\circ} \mathrm{N}-60^{\circ} \mathrm{N}$ & 0.968 & 1.008 & 1.077 \\
$20^{\circ} \mathrm{N}-40^{\circ} \mathrm{N}^{\star}$ & -1.908 & -1.088 & -1.369 \\
$0^{\circ}-20^{\circ} \mathrm{N}^{\star}$ & 0.024 & -0.113 & -0.152 \\
$20^{\circ} \mathrm{S}-0^{\circ}$ & -0.862 & -0.995 & -1.518 \\
$40^{\circ} \mathrm{S}-20^{\circ} \mathrm{S}^{\star}$ & -1.9 & -1.123 & -1.560 \\
$60^{\circ} \mathrm{S}-40^{\circ} \mathrm{S}^{\star}$ & 0.896 & 0.292 & 0.092 \\
$80^{\circ} \mathrm{S}-60^{\circ} \mathrm{S}$ & 1.246 & 1.293 & 0.943 \\
\hline
\end{tabular}

Note: Units are in $\mathrm{mm} \mathrm{d}^{-1}$ and the asterisks show in which regions GECCO estimate is closer to HOAPS than the NCEP. The calculations are performed over common geographical areas for which HOAPS data exist. (The global averages are somewhat smaller for averages over the full model domain. Resulting numbers for NECP (GECCO land mask) and GECCO are -0.43 and -0.28 , respectively.)

this context, Wijffels (2001) summarizes estimates of freshwater transports derived from several oceanic sections.

Globally averaged (over each data domain) net surface freshwater fluxes evaluated from the three data sets over the identical geographic area are on time average $-0.39,-0.55$ and $-0.66 \mathrm{~mm} \mathrm{~d}^{-1}$ for GECCO, NCEP and HOAPS, respectively (see Table 1). Clearly all three data sets have imbalances in freshwater which ideally should be compensated by the global run-off from continents. The recent estimate of run-off for the global ocean (including the Arctic) from Talley (2008) on the basis of data from Dai and Trenberth (2002) is $1.22 \mathrm{~Sv}$, which, when converted, gives $0.30 \mathrm{~mm} \mathrm{~d}^{-1}$. This compares reasonably with the GECCO result (recalling that GECCO does not include the Arctic). However, the values of both NCEP and HOAPS remain substantially biased. The sensitivity of models to such imbalances is indicated by the fact, that the GECCO flux estimate is already causing an increase in the globally averaged salinity field (despite the fact that run-off is included in the estimate) and although the globally averaged halosteric sea level change is unrealistically large, its absolute number remains small but the associated eustatic sea level change is quite unrealistic as discussed by Köhl and Stammer (2008a). The HOAPS surface flux data set therefore would not be suitable to drive a global ocean models over long timescales without any bias correction (in addition to filling in data void regions).

To investigate how variable globally averaged surface freshwater fluxes in the different data sets are, we show in the left-hand panel of Fig. 8 time series of globally averaged deviation from a time-mean surface freshwater flux. A climatological seasonal cycle from each of the data sets is presented in the right-hand panel of the figure. GECCO and NCEP fields both show a seasonal cycle in the global imbalance. The amplitudes of GECCO are larger than NCEP by a factor of 2-3; nevertheless both show a maximum freshwater flux into the ocean during late spring/early summer and a minimum in January/February. The HOAPS global mean shows a less pronounced seasonal cycle as the annual variability for the northern and southern hemisphere tend to compensate each other. However, the time series is dominated by a significant interannual variability a positive peak in 1991 and 1997/1998. The peak in year 1991 represents a bias in the HOAPS product due to the usage of AVHRR Pathfinder data, which even in the most recent version does not properly account for aerosol effects. This results in unrealistic near-surface humidity gradients for several months following the eruption of the Pinatubo in June 1991 and underestimation of the evaporation. A secondary peak in 1997/1998 is most probably caused by the strong ENSO event accompanied by strong precipitation. On the other hand, GECCO shows a negative anomaly until mid 1998 which confirms the interannual change due to freshwater
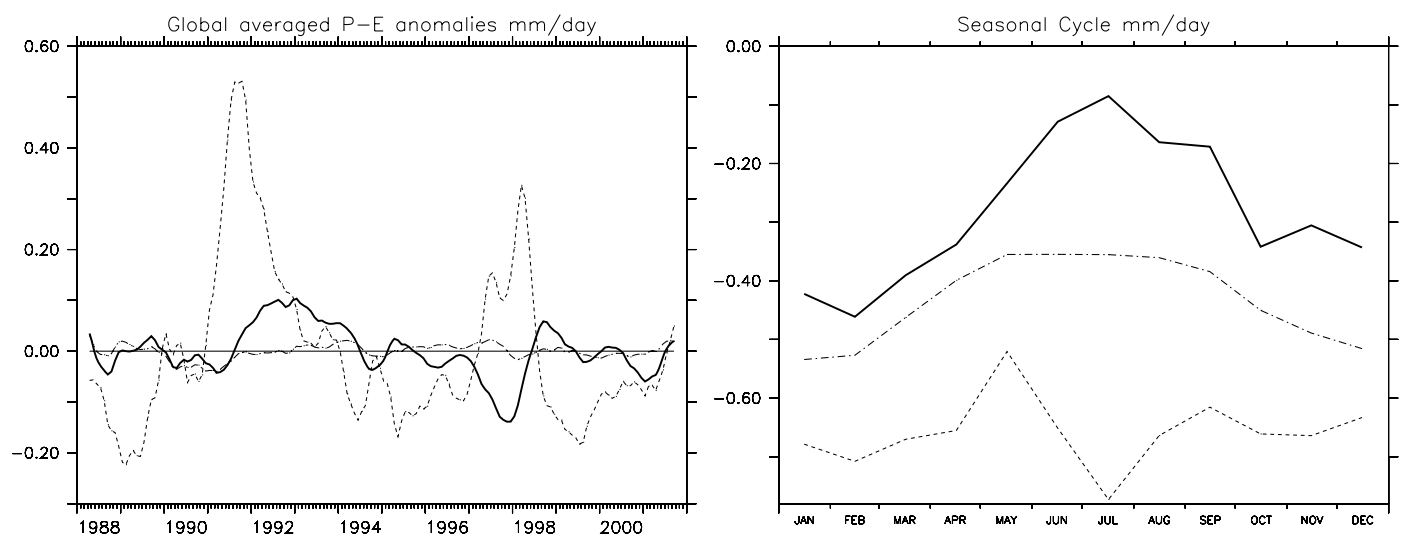

Fig. 8. Time series of the globally averaged freshwater flux fields from GECCO, HOAPS and NCEP (left-hand panel) and their climatological seasonal cycles (right-hand panel). The respective linear trends and the climatological seasonal cycles were removed from the curves in the left-hand panel and a 6-month running mean was applied. In both panels, solid, dashed, and dash-dotted curves show results from GECCO, HOAPS and NCEP, respectively. 
mass variations that Chambers et al. (2000) estimated from sterically corrected sea level changes.

While both anomalies are caused by increased precipitation of the HOAPS product, they also suggest a substantial sensitivity of the retrieval procedure on details of the underlying assumptions about atmospheric conditions and regional uncertainties can be assumed to be at least as large as the global numbers indicated here as difference between HOAPS and GECCO or NCEP results.

The zonally averaged net surface freshwater flux is shown in Fig. 9. The figure shows again the maximum of freshwater input into the ocean in the ITCZ, which in the HOAPS data set is
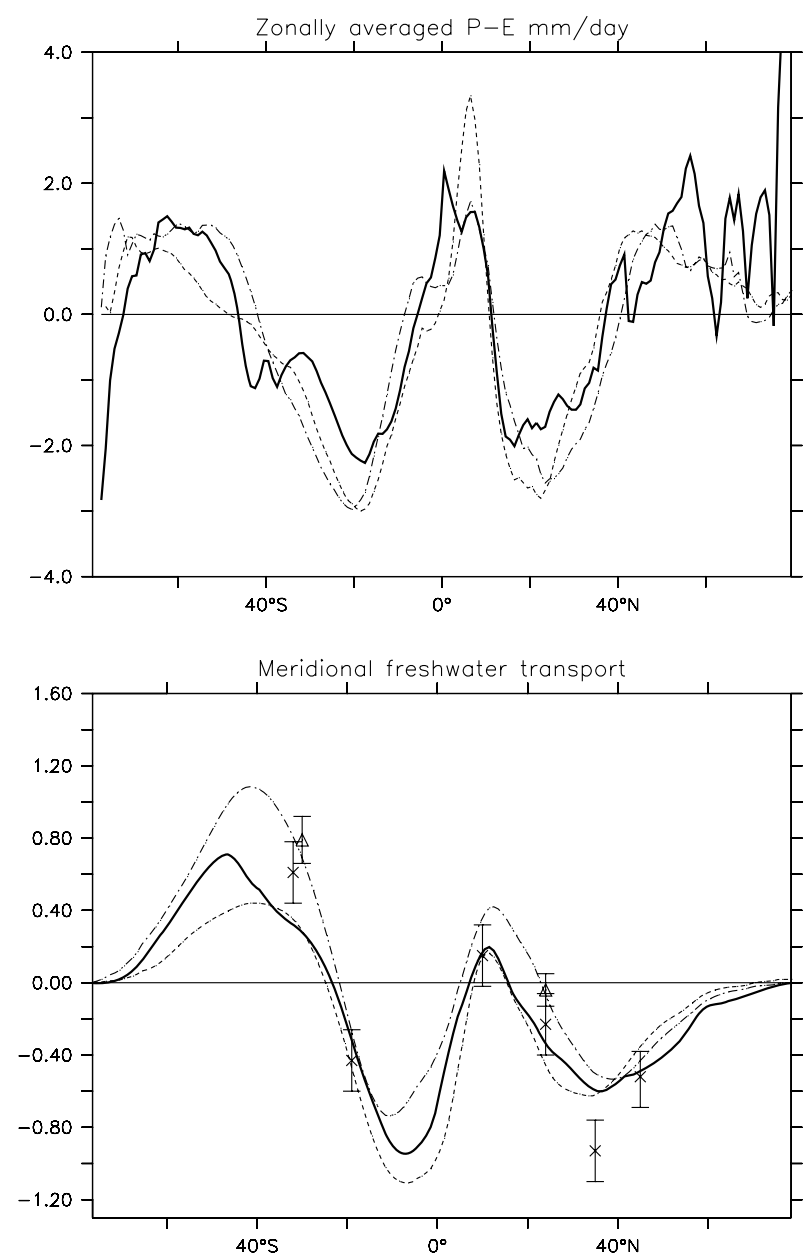

Fig. 9. Zonal integrals of the freshwater fluxes (top panel), and inferred meridional freshwater transport integrated from the southern boundary (bottom panel). The Fekete et al. (1999) run-off was added to all fields and a global biases are removed prior to the meridional integration of the zonally integrated freshwater fluxes. In both panels, solid, dashed and dash-dotted curves show results from GECCO, HOAPS and NCEP, respectively. The crosses and triangles on the bottom panel show estimates of the global freshwater transport and their errors for different latitudes summarized in Wijffels (2001) and Talley (2008) respectively. twice as high than respective results from NCEP and GECCO. Moreover, the figure clearly indicates the split of the ITCZ of the NCEP results into a component north and south of the equator due to the seasonal movement of the ITCZ with the maximum intensity during summer and winter monsoon. GECCO shows a secondary maximum on the equator and corrects away from NCEP in tropics and high latitudes towards or beyond HOAPS. This corresponds to the location of two of the largest rivers, the Amazon and the Congo, and the secondary peak is therefore probably related to corrections to the run-off that the freshwater flux of GECCO includes (compare also Fig. 9). In addition to globally averaged net surface freshwater flux values for each data set, Table 1 shows values for various latitudinal ranges. The table reveals that regional imbalances are much bigger than the global number implying significant redistribution of freshwater in the ocean through ocean transports (see below). From the table it also follows that the biggest deviation of the GECCO freshwater flux from NCEP and HOAPS exists at high latitudes mainly in the Labrador Sea and Greenland (compare Fig. 2). In all the other regions, except for the northern subpolar ocean $\left(40^{\circ} \mathrm{N}-60^{\circ} \mathrm{N}\right)$ and southern tropics $\left(20^{\circ} \mathrm{S}-0^{\circ}\right)$ and polar southern ocean $\left(80^{\circ} \mathrm{S}-60^{\circ} \mathrm{S}\right)$, GECCO is closer to HOAPS.

Meridional freshwater transports can be inferred under the (unlikely but often used) assumption of stationarity by meridionally integrating zonally integrated freshwater fluxes (Fig. 9, bottom panel). For this calculation, the runoff as used in GECCO is added to the other two estimates prior to the integration and the ocean-land masks are taken individually for every product. After cumulatively integrating the freshwater fluxes from the southern boundary at $80^{\circ} \mathrm{S}$, the northward freshwater transport into the Arctic amounts to $0.1,0.7$ and $1.3 \mathrm{~Sv}$ for GECCO, NCEP and HOAPS, respectively (not shown). A small part of the imbalance of the transport calculated from HOAPS satellite data could be attributed to sources and sinks outside the data covered areas since sea ice areas are excluded. However, a larger bias exists due to systematic errors. The imbalance is removed by removing the spatial means for each of the three products. Although it makes the curves more compatible it also removes an meridionally dependent signal of the freshwater transport that is not necessarily a good estimate of the true bias. Northward transport for GECCO and NCEP is found in the regions $80^{\circ} \mathrm{S}-20^{\circ} \mathrm{S}$ and $5^{\circ} \mathrm{N}-20^{\circ} \mathrm{N}$ and southward transport in the tropics north of $20^{\circ} \mathrm{S}$. In the southern hemisphere, HOAPS shows the smallest northward but largest southward transports. The southward freshwater transport in the Northern Hemisphere is similar for all three products having maximum values between 0.5 and $0.6 \mathrm{~Sv}$ at $35^{\circ} \mathrm{N}$.

The comparison to the previous results of Wijffels (2001, her table 6.2.2) shows good agreement with GECCO results, within the error bars (Fig. 9). Recently, Talley (2008) uses coast-tocoast hydrographic sections for geostrophic velocities, salinity and NCEP annual mean winds for the Ekman transport to assess the freshwater transport and divergence for the different ocean 
basins. From her estimates in the Atlantic and Pacific at $24^{\circ} \mathrm{N}$ and in the Atlantic, Pacific and Indian Oceans around $32^{\circ} \mathrm{S}$, we compute two new global estimates which are also included in the plot and which appear in better agreement with HOAPS estimate.

\section{North Atlantic freshwater budget}

Changes in the hydrological cycle over the Atlantic Ocean and associated variations of the surface freshwater flux impact the freshwater balance in the Labrador Sea with possible influence on the deep water formation in the North Atlantic (e.g. Straneo, 2006; Lazier, 1980; Schmidt and Send, 2007; Yashayaevand Clarke, 2008; Curry et al., 2003). Hence, a separate analysis of the characteristics of surface freshwater fluxes of all three estimates over the North Atlantic is warranted. For that purpose we show in Fig. 10 the seasonally averaged differences of surface net freshwater flux GECCO-HOAPS, GECCO-NCEP and HOAPSNCEP for winter (DJF) and summer (JJA). The largest differences between GECCO relative to NCEP and HOAPS show up off the Amazon and Congo River, along the East Greenland current, and in the Labrador Sea, due to the impact of run-off uncertainties and the sea ice melt in the Greenland and Labrador Sea on the GECCO product. Likewise a large anomalous freshwater flux exists along most coast lines in the GECCO product, which is again due to the influence of river discharge that GECCO surface freshwater flux estimates account for.

Although HOAPS masks out most of the regions of sea ice melt, positive freshwater difference between GECCO and HOAPS is found around the areas of sea ice formation. As the maximum difference occurs in fall, this points at a lack of freshwater transport in GECCO that is potentially remedied by the optimization through the creation of anomalous surface freshwater fluxes. Larger freshwater flux relative to HOAPS and NCEP is also found in the region of the subpolar gyre (except for HOAPS summer). For the same reason this is considered as a consequence of ice melt freshwater following the circulation in the Labrador Sea and with the Labrador Current towards midlatitudes. The most uncertain area is the ITCZ, where HOAPS freshwater flux is the largest all year round. GECCO shows a tendency to compensate the differences of NCEP to HOAPS all year round, but still it remains weak. Similar difference between GECCO and HOAPS and GECCO and NCEP in the Gulf Stream region have been addressed above and are related to typical deficiencies of the coarse resolution models associated with the western boundary currents, for example, a weak Labrador Current and northward displaced Gulf Stream. Higher resolution (e.g. Smith et al., 2000) is shown to resolve a large part
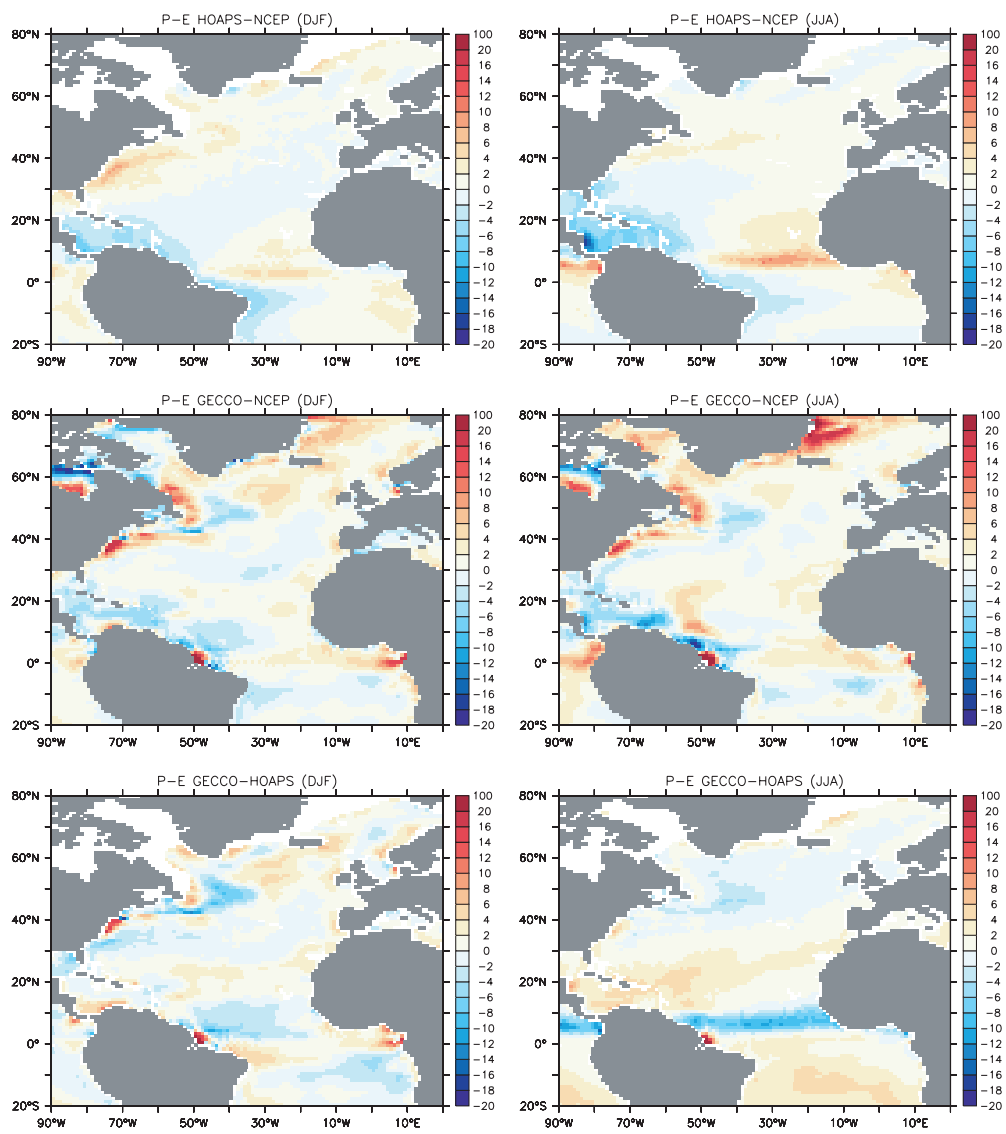

Fig. 10. Differences of seasonal averages of net surface freshwater fluxes HOAPS minus NCEP (top panels), GECCO minus NCEP (middle panels) and GECCO minus HOAPS (bottom panels) for winter (DJF, left-hand column) and summer (JJA, right-hand column). 

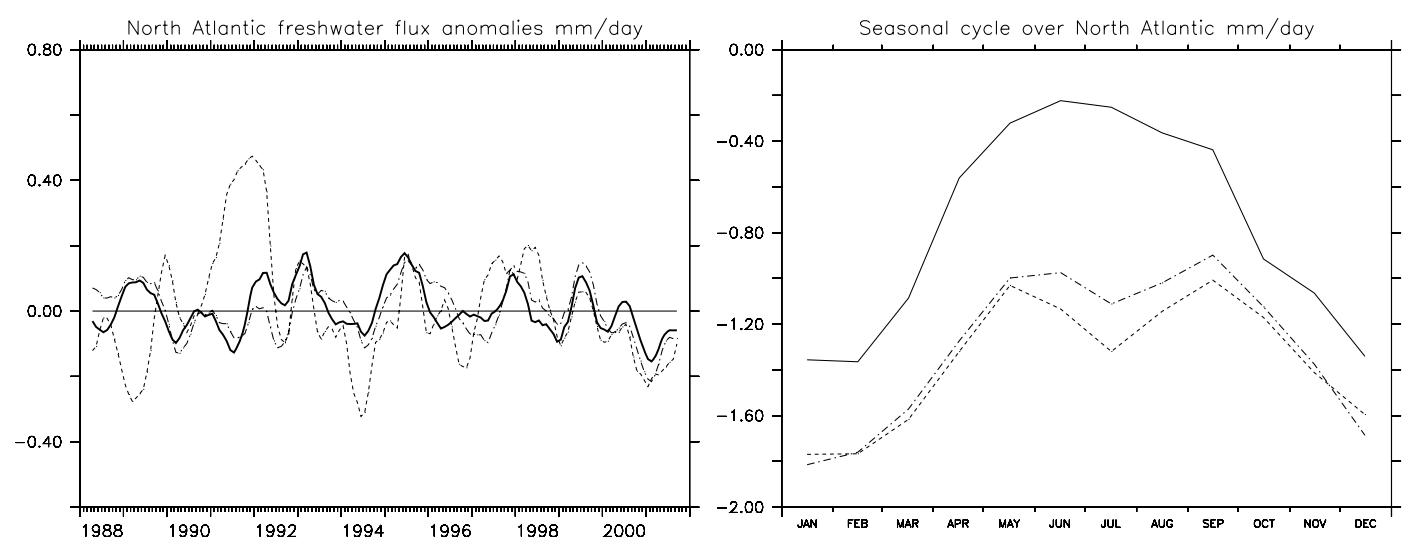

Fig. 11. Freshwater flux time series (left-hand panel) for GECCO, HOAPS and NCEP, averaged over the North Atlantic from $20^{\circ} \mathrm{S}$ to $80^{\circ} \mathrm{N}$ and plotted as function of time after removing the linear trends and the climatological seasonal cycle, which is shown in the right-hand panel. The curves in the left-hand panel were filtered with a 6-month running mean. In both panels, solid, dashed and dot-dashed curves show results from GECCO, HOAPS and NCEP, respectively.

of this bias and is therefore expected that the biases in the flux estimation will be also much smaller. For the surface water mass transformation the representation of the lateral mixing may be more important for the density transformation rates than the model resolution (Gulev et al., 2007).

Time series of North Atlantic averaged P-E flux anomalies (Fig. 11) show a good agreement in the phase of the seasonal cycle over the North Atlantic. However, significant differences exist in terms of interannual changes of minimum and maximum values. Most of all, a decreasing trend of the freshwater flux or increasing evaporative regime is suggested by the HOAPS data set, which is not reproduced in NCEP nor GECCO. The trend largely agrees with the trend in the global HOAPS curve, suggesting that it might be again influenced by uncertainties in the retrieval as discussed above. Thus, the trends in all products are removed prior the plotting in Fig. 11. All three data sets seem to suggest a change in net sea surface freshwater flux occurring over the North Atlantic on a quasi-biannual period. We also note that while the seasonal cycle in all three products is essentially the same, GECCO shows a clear summer minimum in freshwater loss over the North Atlantic, while NCEP and HOAPS show more a plateau of low net freshwater loss between May and September. We also note that GECCO produces a generally lower freshwater loss over the Atlantic as compared to the other two estimates.

The surface net freshwater flux zonally averaged across the Atlantic and associated freshwater transports in the ocean (again using the assumption of stationarity) is shown in Fig. 12. The zonally averaged flux shows a generally good agreement among the products. Larger values in the subpolar regions for GECCO in comparison to the other products is an effect of its inclusion of ice melt. Notable other differences include the large peak in GECCO on the equator due to the already discussed signal of the river run-off corrections and HOAPS shows substantially larger values than the others at $5^{\circ} \mathrm{N}$ probably due to its larger rainfall in the ITCZ.

For the calculation of the freshwater transport, the runoff used in the GECCO estimate is added, as before, to the other two estimates. The positive values indicate a northward transport. The freshwater outflow from the Arctic Ocean and GIN (Greenland, Iceland, Norwegian) Seas is assumed to be zero. All three curves show positive values of the freshwater convergence at $30^{\circ} \mathrm{S}$ which for GECCO is $0.2 \mathrm{~Sv}$ and for NCEP and HOAPS are $0.6 \mathrm{~Sv}$. The maximum southward transport for all three curves is found at $5^{\circ} \mathrm{S}$ and $40^{\circ} \mathrm{N}$. The largest difference of GECCO to the others is an offset to smaller values which starts in the subpolar region and remains near constant until $35^{\circ} \mathrm{S}$ which is related to the additional inclusion of ice-melt in GECCO.

Estimates on the freshwater transport, based on observations, summarized by Wijffels (2001) are included together with the estimates of Talley (2008) in Fig. 12. Since both estimates are divergences referenced to Bering Strait, a freshwater flux integral over the polar region (Bering Strait to $65^{\circ} \mathrm{N}$ ) amounting to about 0.08 Sv (e.g. Baumgartner and Reichel, 1975; Wijffels, 2001; Rudels et al., 2008) had to be removed to be compatible with our results. In the Southern Hemisphere, the GECCO freshwater transport is closest to Wijffel's and Talley's independent estimates. However, the comparison is not straight forward in the Northern Hemisphere because the independent estimates seem to scatter largely at one and the same latitude. However, the independent estimates suggest a stronger southward transport between $24^{\circ} \mathrm{N}$ and $40^{\circ} \mathrm{N}$, which is not reproduced from any of the studied products. Although, Talley (2008) argues that the net transport of $1 \mathrm{~Sv}$ through Bering Strait is of minor importance for the freshwater transport in the Atlantic, this discrepancy is likely due either to the underestimating the freshwater input though the Arctic rivers, or to the importance of the ice-melt. Note, that GECCO appear the closest to the data in the Northern 

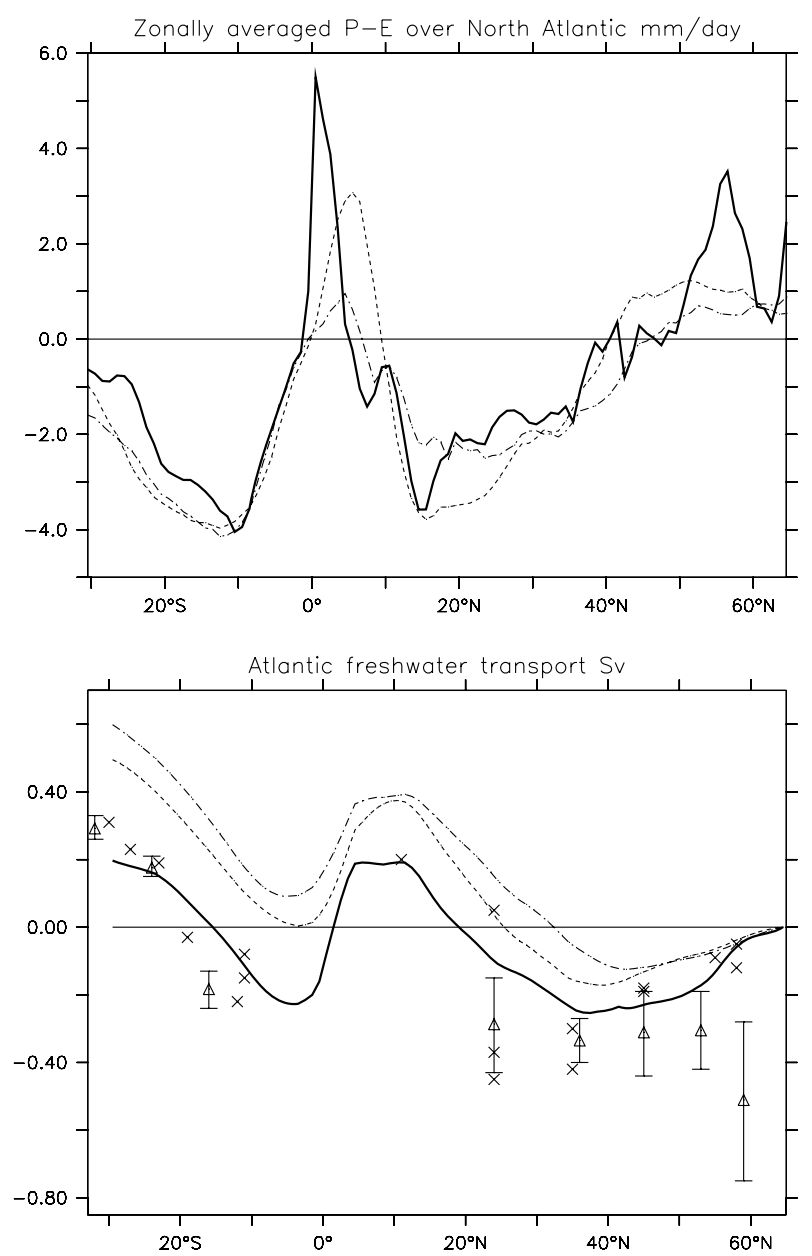

Fig. 12. Zonally averaged freshwater flux over the North Atlantic (top panel) and freshwater transport integrated from $65^{\circ} \mathrm{N}$ (bottom panel). The Fekete et al. (1999) runoff was added prior to the integration. In both panels, solid, dashed and dot-dashed curves show results from GECCO, HOAPS and NCEP, respectively. The crosses and the triangles on the bottom panel show estimates of the Atlantic freshwater transport for different latitudes summarized in Wijffels (2001) and Talley (2008), respectively. As those estimates are originally referenced to the Bering Strait, they were corrected for the Arctic freshwater transport with $0.08 \mathrm{~Sv}$ to be compatible with our results.

Hemisphere as a result of the corrected freshwater fluxes from the assimilated procedure.

Finally, we show in Fig. 13 time series with removed linear trend and the climatological seasonal cycles of the surface freshwater fluxes as they result for various regions of the North Atlantic, notably the western and eastern subpolar gyre, the western and eastern subtropical gyre and the tropical Atlantic. The RMS differences between HOAPS and NCEP, GECCO and NCEP, and GECCO and HOAPS are listed in Table 2. Notable is the close agreement between all products in many respects in the subtropical region, where NCEP shows a lower mean value (by about $0.4 \mathrm{~mm} \mathrm{~d}^{-1}$ ). Likewise, NCEP is lowest in the eastern subpolar and subtropical regions. In the eastern subpolar region HOAPS is closer to NCEP than to GECCO. However we note also that HOAPS appears to have a downward trend suggesting an increase of evaporation occurring not only on basin scale (Fig. 5) but also in most regions of the North Atlantic. As before, the two other data sets do agree on this trend. To what extend it is a bias in HOAPS still has to be quantified. We also note that the time series of P-E averaged over different boxes in the North Atlantic show that GECCO corrects away from NCEP towards HOAPS in the east subtropical and tropical regions. We also note the upward trend in the GECCO flux over the subpolar region (Fig. 5) which potentially could point towards enhanced freshwater input from the Arctic through sea ice advection and melting. However, focusing on the seasonal cycle (see also Table 2), the agreement is somewhat different. A good agreement can only be found between HOAPS and GECCO in the tropics. In all other regions GECCO and NCEP tend to agree better, partly because HOAPS tends to show no clear seasonal cycle at all in those regions.

\section{Concluding remarks}

Estimates of sea surface freshwater fluxes (including continental run-off) are among the most uncertain surface flux fields over the ocean. To test existing estimates of ocean freshwater transports and surface freshwater fluxes resulting from constraining a global ocean circulation model by most data available over a $50 \mathrm{yr}$ period, this paper provides an intercomparison and an attempt to evaluate the three different estimates of surface net freshwater fluxes, one resulting from an atmospheric re-analysis effort (NCEP), one from an oceanographic re-analysis/synthesis effort (GECCO) and one originating purely from independent satellite observations (HOAPS). The goal was to identify common elements in all of them and discuss differences in terms of uncertainties in each of them. Major findings from the analysis can be divided into two part, one concerning the intercomparison of the freshwater flux estimates and a second one addressing the modelling issues and can be summarized as follows.

\subsection{Intercomparison of the freshwater estimates}

All three products agree well on a global scale. However, a detailed analysis revealed regional and seasonal discrepancies. Overall GECCO seems to have moved away from the NCEP/NCAR first guess surface fluxes and is often closer to the HOAPS data set (e.g. Figs. 9 and 12). This holds in terms of the time-mean geographically varying pattern of net P-E; it also holds for the seasonal cycle of net surface freshwater fluxes. As an example, outside boundary current regions, GECCO and HOAPS agree in the amplitude and phase of the seasonal cycle. This in itself is already a strong result since it highlights the use of ocean state estimation to learn more about surface fluxes. 

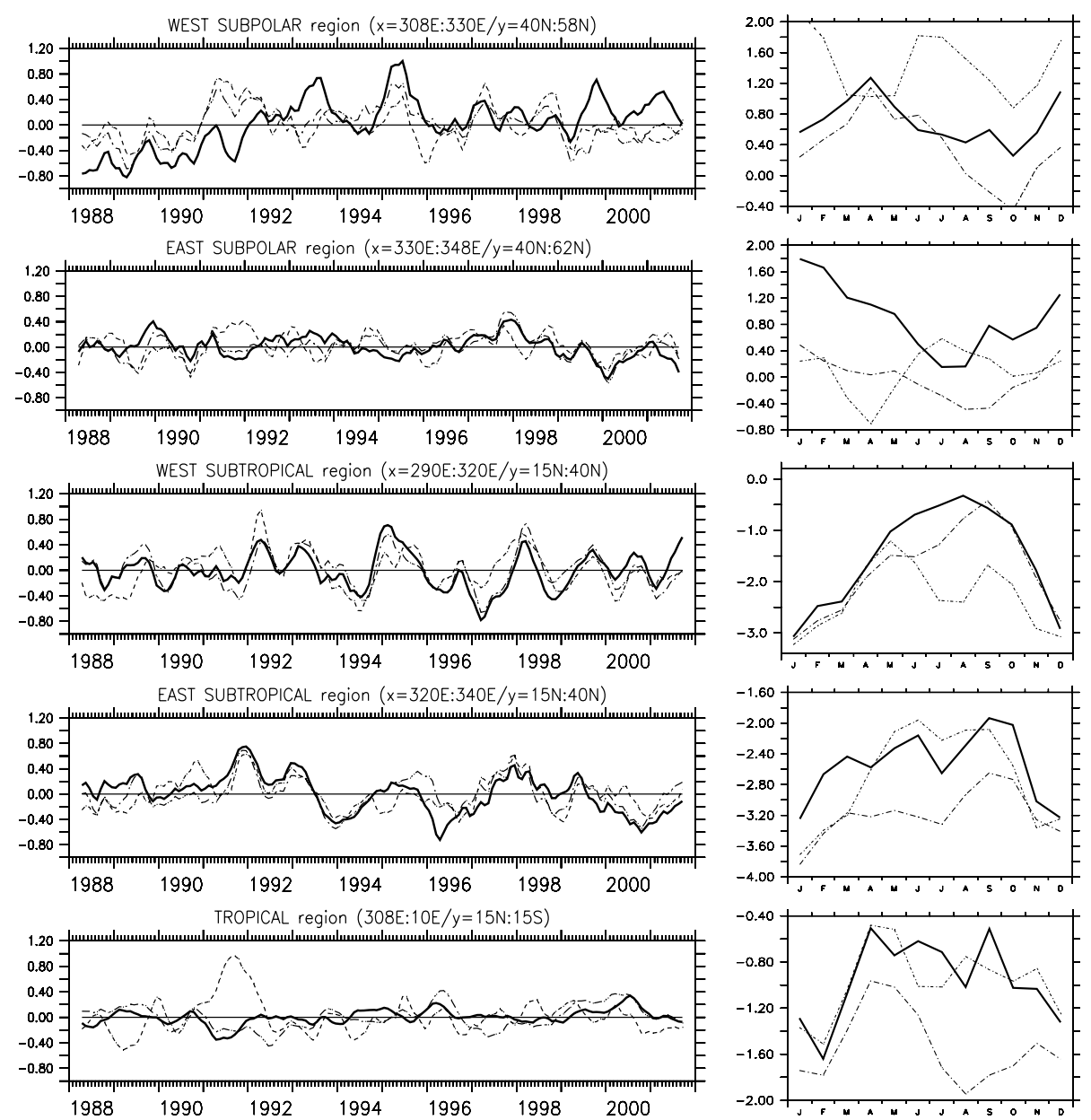

Fig. 13. Time series of the surface freshwater fluxes (in $\mathrm{mm} \mathrm{d}^{-1}$ ) averaged over various regions in the North Atlantic as indicated in the figure (left-hand column). The respective trends and the climatological seasonal cycles (right-hand column) were removed and a 6-month running mean was applied. Regions shown represent (from top to bottom): the western and eastern subpolar Atlantic, the western and eastern subtropical Atlantic and the tropical Atlantic. In all panels, solid, dashed and dash-dotted curves show results from GECCO, HOAPS and NCEP, respectively.

Table 2. RMS difference between the 12 climatological values of HOAPS and NCEP, GECCO and NCEP, and GECCO and HOAPS, globally and for different regions in the North Atlantic

\begin{tabular}{lccc}
\hline Region & HOAPS/NCEP & GECCO/NCEP & GECCO/HOAPS \\
\hline Global & 0.080 & 0.067 & 0.130 \\
West subpolar & 0.559 & 0.285 & 0.518 \\
East subpolar & 0.503 & 0.294 & 0.691 \\
West subtropical & 0.621 & 0.302 & 0.676 \\
East subtropical & 0.461 & 0.227 & 0.380 \\
Tropical & 0.270 & 0.323 & 0.215 \\
\hline
\end{tabular}

GECCO shows an enhanced ITCZ precipitation compared to NCEP but still does not reproduce the amplitudes of HOAPS. This could also point towards a problem in HOAPS precipitation estimates for these regions.

The global freshwater trends point to reduction of the freshwater entering the ocean surface and this feature is significant at the $95 \%$ level. The magnitude of the global negative trend in HOAPS is about 10 times larger compared to the assimilation products. However, all products agree in the freshwater reduction over the equatorial and South East Pacific and over tropical Atlantic Ocean. The negative trend is partly balanced at the Indonesian throughflow and at the Southern Ocean. 
Increased freshwater over the last century over the mid-latitudes in the Southern Hemisphere is a major feature in HOAPS data set and is less pronounced in GECCO and NCEP products. A discrepancy in the trend direction exists in the North Atlantic over the western boundary current, where the three products differ from each other. Different from GECCO, HOAPS shows negative trends, while NCEP does not have any significant trend. The discrepance may come from the shortcomings in the modelled physics in regions with strong currents. It remains to be seen whether the signal in the Southern Ocean over ice covered regions in HOAPS is related to problems in the retrieval procedure or represents a real climate signal.

\subsection{Model efficiency relative to other independent data}

The freshwater variability in GECCO similarly to NCEP is underestimated as compared to HOAPS. To some extent this is related to the fact that not enough information about sea surface salinity existed in the past which would suffice to improve the estimate of the temporal variability of surface net freshwater fluxes and that we need the anticipated satellite observations of sea surface salinity jointly with the salinity observations available now from Argo to further improve our insight into time-varying surface freshwater fluxes and ocean transports of freshwater.

For the NCEP freshwater fluxes, significant biases in the precipitation exist in the tropics where the structures are less well defined and the variability is too low (Trenberth and Guillemot, 1998). However, the NCEP re-analysis is widely used as a global forcing data set for ocean models (Röske, 2006) and is a source for investigating interdecadal variability and trends in the freshwater flux (Josey and Marsh, 2005). The atmospheric NCEP surface freshwater flux is part of the forcing and constrains the control vector in the ocean assimilation procedure. However, it is not consistent with the observed ocean state and the model physics and the optimization therefore results in a new estimate of time-varying net surface freshwater fluxes. Furthermore, the GECCO formulation gives the possibility to reproduce the ice melt inflow and the river discharge, which are a significant part of the global freshwater cycle and are missing in the NCEP re-analysis and HOAPS surface freshwater fluxes.

GECCO surface freshwater flux fields considerably differ from HOAPS and NCEP fields in the polar regions and close to the mouth of major rivers. This is due to the extra freshwater sources from rivers and melting sea ice which are not included in the re-analysis and in the satellite based product. For balancing the freshwater budget of the Atlantic Ocean, the freshwater inflow from the Arctic Ocean is an important component which needs to be included in future GECCO optimizations. Baumgartner and Reichel (1975) calculate around 0.1 Sv freshwater inflow into the Arctic through the Bering Strait and Rudels et al. (2008) report a value of $0.08 \mathrm{~Sv}$. The latter authors also calculate a total of $0.25 \mathrm{~Sv}$ freshwater including 0.09 Sv due to ice export, entering the North Atlantic through various passages.
Consequently, the freshwater transports of NCEP and HOAPS are biased positive in comparison to GECCO, due to the missing freshwater from the ice melt that GECCO includes. However, all three estimates are in the limits of those given by Wijffels (2001) and Talley (2008).

\subsection{Outlook and further work}

While clear improvements are needed for the HOAPS flux product in terms of bias removals, HOAPS nevertheless contains important new information that needs to be included in future ocean syntheses. To do this properly more insight needs to be provided about uncertainties in the HOAPS results. We conclude overall, that the HOAPS freshwater flux is not free of errors but nevertheless serve as an important and independent data set in the comparison.

To improve estimates of surface freshwater fluxes, major efforts are ongoing in climate research to improve our understanding of the global hydrological cycle and the role the ocean plays in this context. Among those efforts are the two upcoming satellite SMOS (ESA) and AQUARIUS (NASA) missions targeted to measure sea surface salinity over the ocean. It is expected that through those novel observations of the changing surface salinity field, new insight will emerge about net surface freshwater fluxes and in ocean transports of freshwater. In this context a new approach to improve our estimates of surface freshwater fluxes over the ocean would be to constrain ocean circulation models with salinity observations (in situ and satellite) along with many other ocean observations, including surface net freshwater flux fields. This paper is a contribution to the discussion to which end ocean syntheses efforts are or will be able to produce realistic ocean freshwater transports and associated surface net freshwater flux fields, including run-off from continents.

\section{Acknowledgments}

Re-analysis surface forcing fields from the National Center for Environmental Prediction/National Center for Atmospheric Research (NCEP/NCAR) are obtained through a computational grant at NCAR. Computational support from the National Center for Atmospheric Research (NCAR) is acknowledged. Supported in part through ONR (NOPP) ECCO grants N00014-991-1049, through NASA grants NAG5-11765, NAG5-12870 and NNG04GF30G, through the DFG (SFB 512) and through the BMBF (Geotechnologie Programm, 03F0421E). The HOAPS project is funded by the German Science Foundation (DFG), the Max-Planck Society (MPG) and the Helmholtz Society (HGF).

\section{References}

Adler, R. F., Kidd, C., Petty, G., Morissey, M. and Goodman, H. M. 2001. Intercomparison of global precipitation products: the third precipitation intercomparison project (PIP-3). Bull. Amer. Meteor. Soc. 82, 1377-1396. 
Andersson, A., Bakan, S., Fennig, K., Grassl, H., Klepp, C. P., and coauthors. 2007. Hamburg Ocean Atmosphere Parameters and Fluxes from Satellite Data - HOAPS-3 - monthly mean. World Data Center for Climate, doi:10.1594/WDCC/HOAPS3-MONTHLY.

Andersson, A. 2009. The HOAPS climatology: evaluation and applications, Ph.D. thesis, Universtä Hamburg, Germany. Berichte zur Erdsystemforschung Nr. 72, Max-Planck-Institut fr Meteorologie, Hamburg, Germany. ISSN 1614-1199

Andersson, A., Bakan, S. and Graß1, H. 2010. Satellite derived North Atlantic precipitation and freshwater flux variability and its dependence on the NAO index. Tellus $\mathbf{6 2 A}$.

Barnier, B. 1998. Forcing the ocean. In: Ocean Modeling and Parameterization, (eds. E. P. Chassignet and J. Verron), Kluwer Academic Publishers, Netherlands, 45-80.

Bauer, P., Lopez, P., Benedetti, A., Salmond, D. and Moreau, E. 2006. Implementation of $1 \mathrm{D}+4 \mathrm{D}$-Var assimilation of precipitation-affected microwave radiances at ECMWF. I: 1D-Var, Quart. J. Roy. Meteor. Soc. 132(620), 2277-2306.

Beranger, K., Barnier, B., Gulev, S. and Crepon, M. 2006. Comparing 20 years of precipitation estimates from different sources over the world ocean. Ocean Dyn. 56, 104-138.

Beranger, K., Siefridt, L., Barnier, B., Garnier, E. and Roquet, H. 1999. Evaluation of operational ECMWF surface freshwater fluxes over oceans during 1991-1997. J. Mar. Syst. 22, 13-36.

Baumgartner, A. and Reichel, E. 1975. The World Water Balance. Amsterdam, the Netherlands, and New York, USA, Elsevier, 179 pp.

Bentamy, A., Katsaros, K. B., Alberto, M., Drennan, W. M., Forde, E. B. and co-authors. 2003. Satellite estimates of wind speed and latent heat flux over the global oceans. J. Climate 16, 637-656.

Bourras, D. 2006. Comparison of five satellite-derived latent heat flux products to moored buoy data. J. Climate 19, 6291-6313.

Bowman, K. P., Homeyer, C. R. and Stone, D. G. 2009. A Comparison of Oceanic Precipitation Estimates in the Tropics and Subtropics. J. Appl. Meteor. Climatol. 48, 1335-1344.

Chambers, D., Chen, J., Nerem, R. and Tapley, B. 2000. Interannual mean sea level change and the Earth's water mass budget. Geophys. Res. Lett. 27(19), 3073-3076.

Curry, R., Dickson, B. and Yashayaev, I. 2003. A change in the freshwater balance of the Atlantic Ocean over the past four decades. Nature 426, 826-829.

Dai, A. and Trenberth, K. E. 2002. Estimates of freshwater discharge from continents: latitudinal and seasonal variations. J. Hydrometeor. 3, 660-687.

Fairall, C. W., Bradley, E. F., Hare, J. E., Grachev, A. A. and Edson, J. B. 2003. Bulk parameterization of air-sea fluxes: update and verification for the COARE algorithm. J. Climate 16, 571-591.

Fairall, C. W., Bradley, E. F., Rogers, D. P., Edson, J. B. and Young, G. S. 1996. Bulk parameterization of air-sea fluxes for Tropical OceanGlobal Atmosphere Coupled-Ocean Atmosphere Response Experiment. J. Geophys. Res. 101, 3747-3764.

Fekete, B. M., Vorosmarty, C. J. and Grabs, W. 1999. An improved global spatially-distributed runoff data set based on observed river discharge and simulated water balance. Unpublished Report, Complex Systems Research Center, University of New, Hampshire, 35pp.

Ganachaud, A. and Wunsch, C. 2003. Large-scale ocean heat and freshwater transports during the World Ocean Circulation Experiment. J. Climate 16, 696-705.
Gulev, S. K., Barnier, B., Knochel, H., Molines, J. M. and Cottet, M. 2003. Water mass transformation in the North Atlantic and its impact on the meridional circulation: insights from an ocean model forced by NCAR-NCAR reanalysis surface fluxes. J. Climate 16, 3085-3110.

Gulev, K., Barnier, B., Molines, J. M., Penduff, T. and Chanut, J. 2007. Impact of spatial resolution on simulated surface water mass transformations in the Atlantic. Ocean Modell. 19, 138-160.

Huang, R. X. and Schmitt, R. W. 1993. The Goldsbrough-Stommel circulation of the world oceans. J. Phys. Oceanogr. 23, 1277-1284.

Janowiak, J. E., Gruber, A., Kondragunta, C. R., Livezey, R. E. and Huffman, G. J. 1998. A comparison of The NCEP-NCAR reanalysis precipitation and the GPCP rain gauge-satellite combined dataset with observational error considerations. J. Climate 11, 2960-2979.

Jourdan, D., Peterson, P. and Gautier, C. 1997. Oceanic freshwater budget and transport as derived from satellite radiometric data. J. Phys. Oceanogr. 27, 457-467.

Josey, S. A. and Marsh, R. 2005. Surface freshwater flux variability and recent freshening of the North Atlantic in the eastern subpolar gyre. J. Geophys. Res. 110, C05008, doi:10.1029/2004JC002521.

Kalnay, E., Kanamitsu, M., Kistler, R., Collins, W., Deaven, D. and co-authors. 1996. The NCEP/NCAR re-analysis project. Bull. Amer. Meteor. Soc. 77, 437-471.

Köhl, A., Dommenget, D., Ueyoshi, K. and Stammer, D. 2006. The global ECCO 1952 to 2001 ocean synthesis. ECCO Report 40, http://www.ecco-group.org/report_series.htm.

Köhl, A., Stammer, D. and Cornuelle, B. 2007. Interannual to decadal changes in the ECCO global synthesis. J. Phys. Oceanogr. 37, 313-337.

Köhl, A. and Stammer, D. 2008a. Decadal sea level changes in the 50-year GECCO ocean synthesis. J. Climate 21, 1876-1890.

Köhl, A. and Stammer, D. 2008b. Variability of the meridional overturning in the North Atlantic from the 50 years GECCO state estimation. J. Phys. Oceanogr. 38, 1913-1930.

Large, W. and Yeager, S. 2004. Diurnal to decadal global forcing for ocean and sea ice models: the data sets and flux climatologies. NCAR Technical Note: NCAR/TN-460+STR. CGD Division of the National Center for Atmospheric Research.

Lazier, J. R. N. 1980. Oceanographic conditions at Ocean Weather Ship Bravo, 1964-1974. Atmos. Ocean 18, 227-238.

Levitus, S., Burgett, R., and Boyer, T. 1994. World Ocean Atlas 1994, Volume 3, Salinity, and Volume 4, Temperature, NOAA Atlas NESDIS 3 \& 4, U.S. Department of Comm., Washington, DC.

Leung, L. R., Qian, Y., Han, J. and Roads, J. 2003. Intercomparison of global reanalyses and regional simulations of cold season water budgets in the western United States. J. Hydrometeorol. 4, 10671087.

MacDonald, A. 1998. The global ocean circulation: a hydrographic estimate and regional analysis. Prog. Oceanogr. 41, 281-382.

Marshall, J., Adcroft, A., Hill, C., Perelman, L. and Heisey, C. 1997a. A finite-volume, incompressible Navier-Stokes model for studies of the ocean on parallel computers. J. Geophys. 102, 5753-5766.

Marshall, J., Hill, C., Perelman, L. and Adcroft, A. 1997b. Hydrostatic, quasi-hydrostatic and non-hydrostatic ocean modeling. J. Geophys. Res. 102, 5733-5752.

Mehta, V. M., DeCandis, A. J. and Mehta, A. V. 2005. Remote-sensingbased estimates of the fundamental global water cycle: annual cycle. J. Geophys. Res. 110, D22103, doi:10.1029/2004JD005672. 
Röske, F. 2006. A global heat and freshwater forcing dataset for ocean models. Ocean Modell. 11, 235-297.

Rudels, B., Marnela, M. and Eriksson, P. 2008. Constraints on estimating mass, heat and freshwater transports in the Arctic Ocean: An exercise. In: Arctic-Subarctic Ocean Fluxes: Defining the Role of the Northern Seas in Climate, (eds. R. Dickson, J. Meincke and P. Rhines), Springer, Dordrecht, Netherlands, 315-341.

Sapiano, M. R. P. and Arkin, P. A. 2009. An inter-comparison and validation of high resolution satellite precipitation estimates with threehourly gauge data. J. Hydrometeor. 10, 149-166.

Schinoda, T., Hendon, H. H. and Glick, J. 1999. Intraseasonal surface fluxes in the tropical western Pacific and Indian Oceans from NCEP reanalyses. Mon. Wea. Rev. 127, 678-693.

Schulz, J., Schlüssel, P. and Graß1, H. 1993. Water vapor in the atmospheric boundary layer over oceans from SSM/I measurements. Int. J. Remote Sens. 14, 2773-2789.

Schlüssel, P. 1995. Passive Fernerkundung der unteren Atmosphäre und der Meeresoberche aus dem Weltraum. vol. 20 of Berichte aus dem Zentrum für Meeres- und Klimaforschung, Reihe A: Meteorologie, Max Planck Institute for Meteorology, Bundesstr. 55, 20146 Hamburg, Germany, ISSN 0947-7128.

Schlüssel, P. 1996. Satellite re-mote sensing of evaporation over sea. In: Radiation and Water in the Climate System: Remote Measurements, Volume 145 of NATO ASI Series, Springer-Verlag, Berlin, Germany, 431-459.

Schmidt, S. and Send, U. 2007. Origin and composition of seasonal Labrador sea freshwater. J. Phys. Oceanogr. 37, 14451454.

Smith, R. D., Maltrud, M. E., Bryan, F. O. and Hecht, M. W. 2000. Numerical representation of North Atlantic Ocean at $1 / 10^{\circ}$. J. Phys. Oceanogr. 30, 1532-1561.

Sohn, B. J., Smith, E. A., Robertson, F. R. and Park, S. C. 2004. Derived over-ocean water vapor transports from satellite-retrieved E2 P datasets. 17, 1352-1365.

Straneo, F. 2006. Heat and freshwater transport through the central Labrador Sea. J. Phys. Oceanogr. 36, 606-628.

Schlosser, A. and Houser, R. 2006. Assessing a satellite-era perspective of the global water cycle. J. Climate 20, 1316-1338.
Stammer, D., Wunsch, C., Giering, R., Eckert, C., Heimbach, P. and co-authors. 2002. The global ocean circulation during $1992-1997$, estimated from ocean observations and a general circulation model. J. Geophys. Res. 107(C9), 3118, doi:10.1029/2001JC000888.

Stammer, D., Ueyoshi, K., Köhl, A., Large, W. G., Josey, S. A. and co-authors. 2004. Estimating air-sea fluxes of heat, freshwater, and momentum through global ocean data assimilation. J. Geophys. Res. 109, C05023, doi:10.1029/2003JC002082.

Swift, C. T., Fedor, L. S. and Ramseier, R. O. 1985. An algorithm to measure sea ice concentration with microwave radiometers. J. Geophys. Res. 90, 1087-1099.

Talley, L. D. 2008. Freshwater transport estimates and the global overturning circulation: shallow, deep and throughflow components. Prog. Oceanogr. 78, 257-303.

Trenberth, K. E., Smith, L., Qian, T., Dai, A. and Fasullo, J. 2007. Estimates of the global water budget and its annual cycle using observational and model data. J. Hydrometeor. 8, 758-769.

Trenberth, K. E. and Guillemot, C. J. 1998. Evaluation of the atmospheric moisture and hydrological cycle in the NCEP/NCAR reanalyses. Climate Dyn. 14, 213-231.

Winterfeldt, J., Andersson, A., Klepp, C. P., Bakan, S. and Weisse, R. 2009. Comparison of HOAPS, QuikSCAT and buoy wind speed in the eastern North Atlantic and the North Sea, IEEE Trans. Geosci. Remote Sens. 47, doi:10.1109/TGRS.2009.2023982

Wijffels, S. E. 2001. Ocean transport of fresh water, in ocean circulation and climate. In: Observing and Modelling the Global Ocean, (eds. G. Siedler, J. Church and J. Gould), Academic Press, London, 475488.

Wunsch, C. 1996. The Ocean Circulation Inverse Problem, Cambridge Univ. Press, New York, 442 pp.

Xie, P., Janowiak, J. E., Chen, M., Wang, W., Shie, C. L. and co-authors. 2007. Examining fresh water flux over global oceans in the NCEP CDAS, CDAS2, GDAS, GFS, and CFS. In: Proceedings of the 32nd Annual Climate Diagnostics and Prediction Workshop, Tallahassee, FL.

Yashayaev, I. and Clarke, A. 2008. Evolution of North Atlantic water masses inferred from Labrador sea salinity series. Oceanography $\mathbf{2 1}$, 30-45. 